\title{
Origins, potency, and heterogeneity of skeletal muscle fibro-adipogenic progenitors - time for new definitions
}

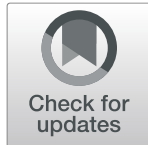

\author{
Osvaldo Contreras ${ }^{1,2,3^{*}}$ (D), Fabio M. V. Rossi ${ }^{4}$ and Marine Theret $^{4^{*}}$ (D)
}

\begin{abstract}
Striated muscle is a highly plastic and regenerative organ that regulates body movement, temperature, and metabolism - all the functions needed for an individual's health and well-being. The muscle connective tissue's main components are the extracellular matrix and its resident stromal cells, which continuously reshape it in embryonic development, homeostasis, and regeneration. Fibro-adipogenic progenitors are enigmatic and transformative muscle-resident interstitial cells with mesenchymal stem/stromal cell properties. They act as cellular sentinels and physiological hubs for adult muscle homeostasis and regeneration by shaping the microenvironment by secreting a complex cocktail of extracellular matrix components, diffusible cytokines, ligands, and immunemodulatory factors. Fibro-adipogenic progenitors are the lineage precursors of specialized cells, including activated fibroblasts, adipocytes, and osteogenic cells after injury. Here, we discuss current research gaps, potential druggable developments, and outstanding questions about fibro-adipogenic progenitor origins, potency, and heterogeneity. Finally, we took advantage of recent advances in single-cell technologies combined with lineage tracing to unify the diversity of stromal fibro-adipogenic progenitors. Thus, this compelling review provides new cellular and molecular insights in comprehending the origins, definitions, markers, fate, and plasticity of murine and human fibro-adipogenic progenitors in muscle development, homeostasis, regeneration, and repair.
\end{abstract}

Keywords: Mesenchymal stromal/stem cell, Fibro/adipogenic progenitor, Fibroblast, Adipocyte, Regeneration, Single-cell RNAseq

\section{Background}

In mammals, skeletal muscle represents 30-40\% of the total body mass, regulating body temperature, metabolism, and physical activity. Comprising the musculoskeletal system, striated muscles are responsible for voluntary and non-voluntary movements. Skeletal muscles are recognized as highly plastic tissue, illustrated by atrophic or hypertrophic changes when disused or trained.

\footnotetext{
*Correspondence: o.contreras@victorchang.edu.au; mtheret@brc.ubc.ca 'Developmental and Stem Cell Biology Division, Victor Chang Cardiac Research Institute, Darlinghurst, NSW 2010, Australia

${ }^{4}$ Biomedical Research Centre, Department of Medical Genetics and School of Biomedical Engineering, University of British Columbia, Vancouver, BC V6T 1Z3, Canada

Full list of author information is available at the end of the article
}

Mammalian adult skeletal muscle has extraordinary regeneration capabilities upon injury, making the organ a perfect model to study regeneration and repair, and investigate the contribution of adult stem and interstitial cells in settings of acute or chronic injury. The muscle connective tissue (MCT) components are the extracellular matrix (ECM) and its stromal cells, which actively produce, maintain, and remodel this dynamic scaffold during development, homeostasis, and after trauma.

Among the several cell types that participate in muscle regeneration, tissue-resident mesenchymal progenitors play a crucial role by providing signaling cues that modulate other muscle-resident cells' function, and actively remodel the ECM during this process. Fibro-adipogenic progenitors

C C The Author(s). 2021 Open Access This article is licensed under a Creative Commons Attribution 4.0 International License, which permits use, sharing, adaptation, distribution and reproduction in any medium or format, as long as you give appropriate credit to the original author(s) and the source, provide a link to the Creative Commons licence, and indicate if changes were made. The images or other third party material in this article are included in the article's Creative Commons licence, unless indicated otherwise in a credit line to the material. If material is not included in the article's Creative Commons licence and your intended use is not permitted by statutory regulation or exceeds the permitted use, you will need to obtain permission directly from the copyright holder. To view a copy of this licence, visit http://creativecommons.org/licenses/by/4.0/. The Creative Commons Public Domain Dedication waiver (http://creativecommons.org/publicdomain/zero/1.0/) applies to the data made available in this article, unless otherwise stated in a credit line to the data. 
(FAPs) have been identified as platelet-derived growth factor receptor alpha (PDGFR $\alpha$, also known as PDGFRA) expressing cells $[1,2]$. A growing body of evidence shows that PDGFR $\alpha+$ FAPs provide regenerative cues to control muscle stem cell (MuSC) expansion, fate, and myogenesis after acute damage and aging [1-7]. Furthermore, the ablation of stromal cells by using mice model expressing the diphtheria toxin receptor (DTR) under the control of the fibroblast activation protein alpha promoter (FAP $\alpha$-DTR) impairs the long-term maintenance of hematopoiesis, muscle mass, and cachexia [8]. To note, FAP $\alpha+$ cells are found in most tissues such as bone, salivary gland, visceral adipose tissue, skeletal muscle, and pancreas; express CD90, CD140a, and SCA-1; and so are most likely to be mesenchymal progenitors, hence FAPs in skeletal muscle [8]. These findings have been confirmed by the Rando laboratory using a knock-in $P D G F R \alpha^{C-}$ ${ }^{r e E R}: R o s a 26^{D T A}$ mice model [7], and more recently, by Tsuchida's group using a similar cell ablation strategy [9]. Indeed, genetic ablation of PDGFR $\alpha+$ lineage cells leads to impaired MuSC expansion and leucocyte infiltration, leading to deficient skeletal muscle regeneration after acute chemical injury and neuromuscular defects and muscle atrophy $[7,9]$. In addition, following limb ischemia, proper muscle revascularization and repair are lost after ablating FAPs [10]. Hence, PDGFR $\alpha+$ FAPs are required for successful muscle regeneration, repair, and maintenance during tissue homeostasis and in pathological states.

Muscle-resident PDGFR $\alpha+$ cells readily initiate fibroblastic colonies (also called fibroblast colonyforming units, CFU-F, (Fig. 1a)) and can clonally differentiate not only into activated fibroblasts/myofibroblasts and adipocytes but also into chondrogenic and osteogenic lineages depending on the context $[1,2$, 10-15]. The plasticity and clonal expansion of muscle FAPs are also seen in humans [16]. However, the effects of damage-induced signals and cues on their plasticity, fate, and functions have only recently begun to be explored. The development of new in vivo lineage tracing tools used to identify and track cells expressing specific markers in various animal and damage models in parallel with the recent emergence of single-cell omics have allowed the identification of a broad spectrum of specific stromal populations and their relative contribution to muscle homeostasis, regeneration, and repair.

\section{The developmental ontology of muscle-resident mesenchymal progenitors}

From the embryo to the adult: role of MCT mesenchymal progenitors on muscle development

Adult MCT is mainly composed of ECM, largely fibrillar collagens type 1 and 3, elastin, fibronectin and proteoglycans, and the supportive matrix-resident stromal cells, also called mesenchymal progenitors or traditionally known as muscle fibroblasts [17-19]. However, compared with the ever-growing knowledge about adult $\mathrm{MCT}$, the composition and the dynamic remodeling of embryonic MCT are poorly understood. While evidence about the ontogeny of interstitial muscle cells exists [20-22], only a paucity of studies have reported their embryonic determination, and hence, the developmental origin and role of these ECM-embedded cells are not yet fully appreciated and understood.

Kardon and colleagues published early evidence of the function of these cells in the formation of limb muscles in the 2000s [23]. The authors described that a mesodermal population of TCF7L2+ cells (formerly known as Tcell factor 4 or TCF-4, a TCF/LEF transcription factor downstream the canonical $\mathrm{Wnt} / \beta$-catenin signaling) regulates the spatiotemporal determination and differentiation of myogenic progenitors and, therefore, regulates limb muscle development in chicks [23]. Limb TCF7L2+ precursors derive from the lateral plate mesoderm in a muscle-specific pattern, but are different from myogenic precursors since they do not form muscle nor express classical myogenic markers (e.g., Pax7) [6, 23, 24]. Thus, myogenic precursors are patterned by extrinsic cues, mostly coming from the MCT, after the cells have migrated through the limb rather than being embryonically predetermined to form particular muscle anatomical structures $[23,25]$. These MCT progenitors also influence the myofiber type of limb and diaphragm muscles in a paracrine fashion [24]. Interestingly, not all limb muscles contain TCF7L2+ cells during mouse embryo development, which suggest a distinct patterning and three-dimensional distribution of these cells in different subtypes, or the existence of MCT progenitors that do not express this marker [26]. Nevertheless, TCF7L2 labels a significant proportion of mammalian stromal nonmyogenic precursors at birth and during adulthood [24, 27, 28]. Additionally, MuSCs and endothelial cells also express $T c f 7 l 2 \mathrm{mRNA}$ and protein, albeit at low levels compared with FAPs [7, 24, 28].

Researchers have argued that vertebrate muscles derive from several developmental sources, adding complexity to our understanding of the different origins of MCT in muscle development. For comprehensive reviews, see: [20-22]. Like myogenic precursors, MCT progenitors originate from different and distinct structural origins during embryonic development. In mammals, these include the somites for axial-trunk muscles [29], the lateral plate mesoderm for limb muscles [23, $30]$, the neural crest cells (NCCs) for head and neck muscles [31-34], and the transient developmental structure originating from the somites called pleuroperitoneal folds (PPFs) for the diaphragm [35]. Remarkably, Merrell and colleagues demonstrated that PPFresident $\mathrm{TCF} 7 \mathrm{~L} 2^{+} / \mathrm{GATA}^{+} \mathrm{CT}$ precursors regulate the 


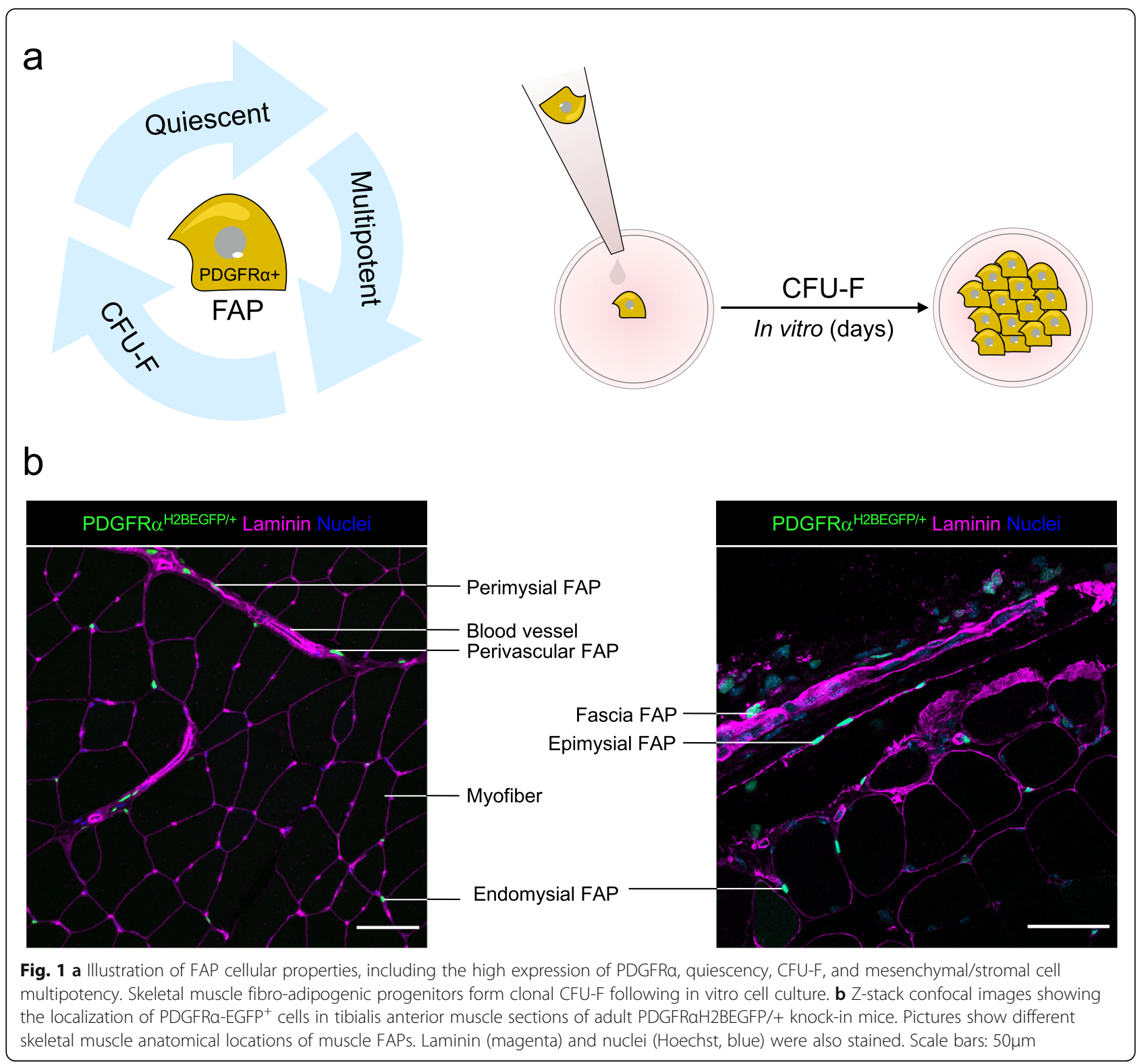

development of the diaphragm and participate in the etiology of congenital diaphragm hernias $(\mathrm{CDH})$, a type of fibroproliferative developmental disorder [35]. The authors also demonstrated that Gata4 null mutations in CT progenitors expressing Paired related homeobox 1 (Prx1) could cause CDH during diaphragm development. These studies indicate that the aberrant behavior of PPFs CT progenitors can cause congenital muscle diseases like $\mathrm{CDH}$ [35].

The studies of Logan's group have also helped to advance our understanding of the developmental role of MCT precursors in muscle morphogenesis. Initially, through a combination of conditional deletion and advanced imaging techniques, they demonstrated the crucial participation of T-box transcription factors, Tbx4 and $T b x 5$, in determining the formation of muscles and tendons of the musculoskeletal system [36]. Interestingly, they found that the myoblast-specific loss of $T b x 5$ does not affect the correct positioning of myogenic precursors. However, genetic deletion of $T b x 5$ and $T b x 4$ in the mesenchyme (paired related homeobox (Prx) expressing lineage), resulted in the perturbation of MCT organization, and therefore, caused mispatterned muscle limbs. Although the authors observed no changes in the expression of $T c f 7 l 2$ in the absence of $T b x 4 / 5$, the lack of these transcription factors impaired the spatiotemporal distribution of TCF7L2+ cells [36]. Remarkably, the Holt-Oram syndrome, known for leading to skeletal abnormalities and congenital heart disease, is caused by mutations in the Tbx5 gene [37]. The study of Hasson 
et al. reinforces the model in which MCT gives rise to muscle pre-patterned structures to guide myogenic precursors during development and further demonstrated that extrinsic MCT-derived cues are critical for muscle morphogenesis. Without surprise, the Transforming Growth Factor beta (TGF- $\beta$ ) signaling pathway is involved in this process. Indeed, Kutchuk et al. demonstrated that embryonic myofibers and $\mathrm{C} 2 \mathrm{C} 12$ myoblasts express Lysyl Oxidase (Lox, an enzyme required for cross-linkage formation in elastin and collagen) and that its deletion upregulates the TGF- $\beta$ signaling. $\operatorname{Lox}^{-/-} \mathrm{mu}-$ tants display MCT disorganization and delayed myogenesis [38]. Thus, this study illustrates the homeostatic cross-talk between MCT and muscle cells during limb musculoskeletal system development.

The above-proposed model was recently corroborated in detail by Besse and colleagues [39]. These authors took full advantage of an array of labeling and imagingbased studies, mouse genetics, and transcriptomic analyses to establish how individual muscle bundles are generated and established, shedding profound lights on the role of MCT precursors on muscle morphogenesis at unprecedented resolution. They provided a compelling demonstration that muscle morphogenesis is primarily orchestrated by CT mesenchymal progenitors via the secretion of matrix-modifying proteoglycans [39]. Thereby, through the expression and the secretion of a myriad of chemoattractants, ECM components, and growth factors, these stromal cells promote a variety of responses in myogenic precursors, including repulsion, attraction, migration, and patterning [20]. Hence, the MCT creates a developmental pre-pattern that orientates and controls the positioning of myogenic precursors that differentiate into myofibers forming muscle bundles and, consequently, will serve to define the size and shape of muscles, the orientation of its myofibers, and points of origin and insertion on bones [23, 25, 36, 39, 40].

The notion that MCT cells participate in muscle morphogenesis leads to wonder what determines the spatiotemporal dynamics and positional information of MCT precursors. Hox genes are a set of genes coding for transcription factors that specify segment identity and provide positional information during animal development [41]. Among them, the caudal Hox11 genes participate in determining the proximal-distal axis of the musculoskeletal system of limbs [42-45]. Hoxa11 is broadly expressed through the distal primordium of limb buds at E10.5, but later on, at E14.5, it is exclusively expressed in the CT of tendons, perichondrium, and TCF7L2+ cells, but not in endothelial cells, chondrocytes, osteocytes, nor myogenic precursors [46]. Genetic deletion of Hoxa11/Hoxd11 paralogs, which have a prominent role in patterning bones during development, leads to severe defects in the pattern and regionalization of muscles and tendons, independently of bone defects [46]. Altogether, these results not only demonstrate a previously unappreciated function of Hox genes for proper patterning and integration of muscles, tendons, and bones but also illustrated that CT spatiotemporal dynamics participate in the integration of the musculoskeletal system as a whole. Further studies should detail how, when and what factor(s) modulate the spatiotemporal dynamics and positional fate of muscle connective tissue cells.

\section{Searching for cell-type-specific markers of muscle stromal fibro-adipogenic progenitors}

In adult tissue, two studies characterized a population of interstitial muscle-resident progenitors with spontaneous mesenchymal stem/stromal cell (MSC) potential towards fibrous myofibroblast and fatty differentiation [1, 2]. Using fluorescence-activated cell sorting (FACS) of digested mouse skeletal muscle, our laboratory identified and named these cells as fibro-adipogenic progenitors (FAPs) based on their spontaneous differentiation along these lineages [1]. We characterized these progenitors as lineage-negative (Lin-, not expressing hematopoietic (CD45), endothelial (CD31, also known as PECAM-1) or myogenic markers ( $\alpha 7$-INTEGRIN) and positive for Stem cell antigen-1 (SCA-1) and CD34 cell-surface antigen expression. Interestingly, while quiescent MuSCs, endothelial cells, and a subset of hematopoietic cells express CD34, its genetic deletion impairs MuSC but not FAP proliferation [47]. We also demonstrated that most Lin-/ $\alpha 7$ INTEGRIN-/SCA-1+ cells express high levels of the receptor tyrosine kinase PDGFR $\alpha$ [1]. Similarly, Uezumi et al. characterized the same population using a different gating strategy. They used CD45, CD31, and $\mathrm{Sm} / \mathrm{C} 2.6$ (MuSC marker) as a negative selection and $\mathrm{CD} 140 \mathrm{a}$ (PDGFR $\alpha)$ as positive. They showed that LinPDGFR $\alpha+$ cells express a low level of PDGFR $\beta$ and can differentiate in adipocytes, myofibroblasts, and chondrocytes in vitro [2]. They also observed that muscle PDGF $R \alpha+$ cells were perivascular but did not co-localize with NG2, suggesting that PDGFR $\alpha+$ cells are not pericytes [2].

PDGFR $\alpha+$ cells reside in the muscle interstitium and are more abundant in the epimysium and perimysium than in the endomysium. Although most muscleresident PDGFR $\alpha+$ progenitors are in close association with blood vessels $[1,2,48]$, they are distinct from pericytes. Indeed, pericytes are embedded within the endothelium basement membrane, but PDGFR $\alpha+$ cells reside outside of vessels. The localization of FAPs is evident around large blood vessels, in which they adopt an adventitial position. With rare exceptions in organs other than muscle, PDGFR $\alpha$ cells do not express defining pericyte markers like Cspg4 (NG2), Rgs5, Pdgfr $\beta$, or Mcam 
(CD146) $[2,48,49]$. Notably, while FAPs were initially described in murine muscles, growing evidence indicates that human FAPs have a similar phenotype and functions to mouse FAPs [16, 50-54]. In summary, FAPs (historically called fibroblasts) and the ECM they actively secrete and modify are both significant constituents of the interstitium and perivascular CT.

Distinct subpopulations of CT progenitors exist and express an array of proteins and transcription factors, albeit at variable levels. In the mouse embryo, CT progenitor markers include PDGFR $\alpha$, TCF7L2, TBX3/4/5, HOX11, and the Odd-skipped transcription factors OSR1 and OSR2 [21, 23, 26, 40, 55, 56] (Table 1). In murine adult muscles, the large majority of CT fibroadipogenic progenitors express PDGFR $\alpha$, SCA-1 (also known as Ly6A/E), CD90 (THY1), CD34, TCF7L2, HIC1, VIMENTIN, DECORIN, and ADAM12 but few of these markers are specific and unique for this heterogeneous population of cells (discussed below) [1, 11, 12, $28,57,59,61,63,66]$ (Table 1). Of note, murine adult muscle PDGFR $\alpha+$ FAPs express low levels of Osr1, which increases upon acute injury in a small subset of FAPs, suggesting the participation of regulatory mechanisms that tightly turn on the expression of Osr1 resembling developmental-like programs [67]. Remarkably, damage-activated OSR1+ FAPs proliferate faster compared with OSR1- FAPs [67], suggesting that either OSR1 modulates the expansion and functions of FAPs, or it represents an activation marker whose expression increases in proliferating cells.
Recently, Gli1 (also known as glioma-associated oncogene 1) expression has been shown to label a subpopulation of muscle FAPs with higher clonogenicity and reduced adipogenic differentiation than Gli negative FAPs [65]. Perivascular cells expressing the zinc finger protein Gli1 undergo proliferative expansion and generate myofibroblasts after kidney, lung, liver, and heart injury [68] and heart injury [6], suggesting that Gli1+ cells are likely a FAP subpopulation as recently shown in skeletal muscles [69].

In humans, cell-surface markers like PDGFR $\alpha$, CD201, CD166, CD105, CD90, CD73, and CD15 identify skeletal muscle FAPs (Table 2) $[16,51,53,54,64,71,72]$. Remarkably, the expression of SCA-1 defines a particular cluster of stromal cells within the murine FAP population with different potency and properties in vivo and in vitro, both in the skeletal muscle and heart $[66,73]$. However, as SCA-1 does not have a human homolog, its use to identify FAPs is limited by the absence of this antigen in humans.

Recently, we showed that the majority of cells expressing the protein-coding gene Hypermethylated in Cancer 1 (Hicl) correspond to quiescent muscle-resident FAPs in mice [48]. In adult muscles, $\mathrm{HIC1}+$ progenitors reside in the interstitial space and the myotendinous junctions. In addition to FAPs, small subsets of pericytes (SCA-1-, RSG5+ cells) and tenogenic cells (SCA-1-, SCX+ and FMOD+ cells) express HIC1. Therefore, the expression of Hic1 comprises a larger proportion of mesenchymal stromal progenitors compared with the expression of PDGF $\mathrm{R} \alpha$, which is limited to FAPs [48]. Along with others, we have confirmed that cardiac PDGFR $\alpha+$ cells also exhibit

Table 1 Summary of endogenous murine skeletal muscle fibro-adipogenic progenitors

\begin{tabular}{|c|c|c|c|c|c|c|c|}
\hline $\begin{array}{l}\text { Murine } \\
\text { cell }\end{array}$ & $\begin{array}{l}\text { Canonical } \\
\text { Markers }\end{array}$ & $\begin{array}{l}\text { Alternative } \\
\text { markers }\end{array}$ & $\begin{array}{l}\text { Negative } \\
\text { markers }\end{array}$ & Localization & Differentiation potential & Additional comments & References \\
\hline $\begin{array}{l}\text { Embryonic- } \\
\text { fetal FAPs }\end{array}$ & $\begin{array}{l}\text { PDGFRa } \\
\text { TCF7L2/ } \\
\text { TCF4 } \\
\text { Osr1 }\end{array}$ & $\begin{array}{l}\text { Osr2 } \\
\text { Hox11 } \\
\text { Tbx3 } \\
\text { Tbx4 } \\
\text { Tbx5 } \\
\text { Sca-1 }{ }^{\text {a }} \\
\text { CD34 }^{\text {a }} \\
\text { Adam-12 }^{\text {Ada- }} \text { Tie }\end{array}$ & $\begin{array}{l}\text { CD45 } \\
\text { CD31 } \\
\text { Ter119 } \\
\text { a7- } \\
\text { Integrin }\end{array}$ & $\begin{array}{l}\text { Muscle- } \\
\text { associated } \\
\text { connective } \\
\text { tissue and } \\
\text { muscle } \\
\text { interstitium }\end{array}$ & $\begin{array}{l}\text { Robust in vitro adipogenic } \\
\text { and fibrogenic differentiation } \\
\text { but low chondrogenic and } \\
\text { no detectable osteogenic or } \\
\text { myogenic potential. Osr1+ } \\
\text { progenitors also give rise to } \\
\text { embryonic fibroblast-like cells } \\
\text { in the dermis and FABP4+ } \\
\text { adipocytes in white fat pads }\end{array}$ & $\begin{array}{l}\text { Little is known about their } \\
\text { origin, fate, gene } \\
\text { regulation, function, } \\
\text { stemness, and self- } \\
\text { renewal }\end{array}$ & {$[24] ;[26] ;[57] ;$} \\
\hline Adult FAPs & $\begin{array}{l}\text { PDGFRa } \\
\text { SCA-1 }\end{array}$ & $\begin{array}{l}\text { Hic1 } \\
\text { CD90 } \\
\text { Decorin } \\
\text { (Dcn) } \\
\text { PDGFRß } \\
\text { Col1a1 } \\
\text { TCF7L2/ } \\
\text { TCF4 } \\
\text { CD34 } \\
\text { Adam-12 }^{\mathrm{b}} \\
\text { Tie-2 }^{\mathrm{c}} \\
\text { Gli1 }^{\mathrm{d}}\end{array}$ & $\begin{array}{l}\text { CD45 } \\
\text { CD31 } \\
\text { Ter119 } \\
\text { a7- } \\
\text { Integrin } \\
\text { NG2/ } \\
\text { Cspg4 } \\
\text { Rsg5 }\end{array}$ & $\begin{array}{l}\text { Fascia, } \\
\text { epimysium, } \\
\text { perimysium, and } \\
\text { endomysium; } \\
\text { abundant as } \\
\text { perivascular cells }\end{array}$ & $\begin{array}{l}\text { Adipocytes, myofibroblasts, } \\
\text { osteocytes, and } \\
\text { chondrocytes after muscle } \\
\text { injury and in vitro, with no } \\
\text { myogenic potential }\end{array}$ & $\begin{array}{l}\text { Required for adult skeletal } \\
\text { muscle regeneration and } \\
\text { homeostasis; cellular and } \\
\text { molecular dysfunction in } \\
\text { pathology and disease }\end{array}$ & $\begin{array}{l}{[1] ;[11,12,27,28] ;} \\
{[13] ;[14] ;[58] ;[58] ;} \\
{[59] ;[60] ;[61] ;[62],} \\
{[2,15,53,63,64] ;}\end{array}$ \\
\hline
\end{tabular}


Table 2 Summary of endogenous human skeletal muscle fibro-adipogenic progenitors

\begin{tabular}{|c|c|c|c|c|c|c|c|}
\hline $\begin{array}{l}\text { Human } \\
\text { cell }\end{array}$ & $\begin{array}{l}\text { Canonical } \\
\text { Markers }\end{array}$ & $\begin{array}{l}\text { Alternative } \\
\text { markers }\end{array}$ & $\begin{array}{l}\text { Negative } \\
\text { markers }\end{array}$ & Localization & Differentiation potential & $\begin{array}{l}\text { Additional } \\
\text { comments }\end{array}$ & References \\
\hline $\begin{array}{l}\text { Embryonic- } \\
\text { fetal FAPs }\end{array}$ & PDGFRA & $\begin{array}{c}\text { DCN } \\
\text { FN1 } \\
\text { LUM } \\
\text { OSR1 } \\
\text { POSTN } \\
\text { FAP } \\
\text { THY1/CD90 } \\
\text { VIM } \\
\text { NT5E/CD73 } \\
\text { COL1A1 } \\
\text { COL1A2 } \\
\text { COL3A1 } \\
\text { PTN } \\
\text { OGN } \\
\text { FBLN5 }\end{array}$ & $\begin{array}{l}\text { PAX3 } \\
\text { PAX7 }\end{array}$ & $\begin{array}{l}\text { Similar to what is } \\
\text { found in mouse } \\
\text { development, } \\
\text { although not } \\
\text { evaluated in detail }\end{array}$ & $\begin{array}{l}\text { Not evaluated but probably } \\
\text { similar to what is found in } \\
\text { mouse development }\end{array}$ & $\begin{array}{l}\text { No information } \\
\text { about their origin, } \\
\text { gene regulation, } \\
\text { function, and } \\
\text { potency }\end{array}$ & {$[70]^{\mathrm{a}}$} \\
\hline Adult FAPs & $\begin{array}{l}\text { PDGFRA, CD34 } \\
\text { (when negative } \\
\text { for CD56, CD31 } \\
\text { and CD45) }\end{array}$ & $\begin{array}{l}\text { CD201 } \\
\text { CD166 } \\
\text { CD105 } \\
\text { CD90 } \\
\text { CD73 } \\
\text { CD34 } \\
\text { CD15 } \\
\text { COL1A1 } \\
\text { TCF7L2/ } \\
\text { TCF4 }\end{array}$ & $\begin{array}{l}\text { CD31 } \\
\text { CD45 } \\
\text { CD56 } \\
\text { a7- } \\
\text { Integrin } \\
\text { NG2/ } \\
\text { CSPG4 } \\
\text { RSG5 }\end{array}$ & $\begin{array}{l}\text { Fascia, epimysium, } \\
\text { perimysium, and } \\
\text { endomysium; } \\
\text { abundant as } \\
\text { perivascular cells }\end{array}$ & $\begin{array}{l}\text { Adipocytes, myofibroblasts, } \\
\text { osteocytes, and chondrocytes } \\
\text { in diseased states and in vitro. } \\
\text { Lack of myogenic potential }\end{array}$ & $\begin{array}{l}\text { Increased numbers } \\
\text { in diverse } \\
\text { pathologies }\end{array}$ & $\begin{array}{l}{[16] ;[51] ;} \\
{[71] ;[72] ;} \\
{[52] ;[53} \\
54,64]\end{array}$ \\
\hline
\end{tabular}

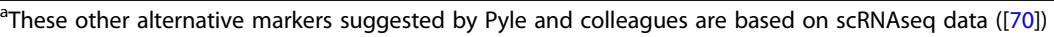

multilineage properties in vivo and in vitro [11, 12, 73-75]. In the murine heart, $\mathrm{HIC1}+$ progenitors represent a significant proportion of cardiac FAPs [73]. HIC1 (also known as ZBTB29) is a transcription factor involved in quiescence and cell cycle control $[76,77]$. Consistent with these roles, the conditional deletion of Hic1 induces aberrant cell activation and proliferation of FAPs, impairing muscle regeneration following acute damage and leading to spontaneous development of arrhythmogenic cardiomyopathy-like pathology and signs in the mouse heart $[48,73]$. Thus, the unrestrained activation of these progenitor cells and the consequent generation of differentiated progeny are potential pathological drivers of disease.

We claim that the heterogeneity of FAP markers makes sense in a context where the upregulation and downregulation of cell-specific makers participate in modulating the commitment of FAPs into a transitional cell state or differentiation process during lineage progression in response to injury or in disease states. Hence, FAP heterogeneity might contribute to restricting or priming the multipotency of PDGFR $\alpha+$ FAPs. These are important issues to explore in future research.

\section{Adult muscle connective tissue and PDGFRa+ progenitors}

Adult skeletal muscle contains several cell types that work in unison under tightly regulated conditions to maintain homeostasis. Adult mammalian muscle is a remarkable exception to the low regenerative potential of several organs and tissues like the heart. Before we start highlighting the contribution of endogenous PDGFR $\alpha+$ cells to mammalian skeletal muscle homeostasis, regeneration, and repair, it is worth revisiting the terminology in this area. Muscle regeneration is defined as the specific substitution or replacement of lost tissue, eventually leading to full restoration of muscle strength. This regenerative capacity relies on resident adult unipotent stem cells (also known as satellite cells), which are quiescent but activate to rebuild this tissue upon injury $[6$, 78-80].

In comparison, skeletal muscle repair aims to safeguard the remaining function of muscle following solutions of continuity after partial loss of tissue due to massive traumas or chronic insults such as repetitive injuries, disease, and aging. Thus, muscle repair often entails replacing lost myofibers with scar tissue, which acts as a bridge between areas still capable of contraction (for review of tissue regeneration and repair see [81-83]. Therefore, while repair restores muscle integrity, regeneration accounts for restoring tissue function. As observed in other mammalian regenerative tissues such as the liver [81, 84], the form and periodicity of damage can impair the ability of the skeletal muscle to return to homeostasis [59, 85, 86]. Therefore, the current established dual role that PDGFR $\alpha+$ cells play in acute (regenerative) and chronic damage (reparative/ degenerative) suggests that the organization of their intracellular signaling network may integrate opposite complementary signals whose relative strength mainly depends on the type, extension, and frequency of the 
injury. For this review, we redefine the fate and heterogeneity of muscle-resident PDGFR $\alpha+$ progenitors and explain their multilineage potentials.

\section{The adult muscle connective tissue}

The muscle environment is complex in structure and several heterogeneous cell types co-exist within it to regulate its function and structure. Although skeletal muscles have an intricate network of blood vessels and nervous tissue, most of their mass is comprised of myofibers. In adults, MCT, which accounts for $1-20 \%$ of the total dry mass of muscles, surrounds, protects, and interconnects these primary components $[19,87,88]$. The amount of CT varies significantly from one muscle to another, depending on the anatomical location and physiological function of particular muscles [89]. The adult MCT follows the nomenclature of fascia, epimysium, perimysium, and endomysium accordingly to its location and arrangement within the tissue [90, 91] (Fig. 1b). The topological organization of the covering connective tissue from the outside is described as follows: the fascia, the CT outside the epimysium that surrounds and separates the muscles; the epimysium, which surrounds each muscle group, linking them to the tendons at the myotendinous junctions; the perimysium, which consists of collagen-rich structures that surround the fascicles and interconnect with the epimysium; and the endomysium, which represents a modified basement membrane unsheathing individual myofibers and interconnects to the perimysium $[19,91,92]$ (Fig. 1b). These four levels of stromal organization describe the interconnected ECM compartments within muscles. Although each compartment is distinguished by its anatomical position, it is difficult to discriminate each of these ECM compartments in terms of their protein and cellular composition. Remarkably, MCT not only determines the macro and microstructures of embryonic and adult muscles but also connects the myofibers to produce and transmit force. As a result, it increases not only the efficiency of force generation but also protects myofibers from excessive stretching, supporting muscle regeneration and cellular mechanosensation [17-19].

\section{Muscle-resident fibro-adipogenic progenitors: definitions and identity}

Historically, the observation of ECM proteins, such as collagens, being produced and deposited in skeletal muscle suggested the existence of a resident collagenproducing cell within the tissue $[17,18,90]$. Later, numerous observations of CT hyperplasia and interstitial proliferation associated with healing scars in skeletal muscle diseases, including congenital muscular dystrophies, immobilized muscles, and neuromuscular disorders (e.g., amyotrophic lateral sclerosis and denervation) radically increased the attention paid to MCT [93-100]. In order to understand MCT development, establishment, and remodeling, it is crucial to consider the stromal cells that participate in these processes. A critical and challenging step towards a complete understanding of MCT biology has been the identification of a heterogeneous population as the primary effector of ECM deposition and remodeling $[11,12,17,18,48,62]$. Increasing evidence suggests that there are distinct subsets of stromal cells located in discrete yet similar anatomical positions during muscle development and into adulthood [20-22]. This stromal cellular diversity and heterogeneity have been an obstacle to attributing the primary role for matrix deposition to a specific subset of stromal cells.

Jackson and colleagues reported the existence of tissue-resident mesenchymal progenitors with multilineage differentiation capabilities in damaged human muscle over a decade ago [101]. Today, thanks to the great effort of many researchers, we know that adult MCT is mainly produced by muscle-resident PDGFR $\alpha+$ cells with multilineage progenitor properties and a fibroblast-like phenotype, called FAPs. Increasing evidence suggests that these muscle-resident cells are the primary cellular source of regenerative matrix deposition as well as scarring following muscle injury, disease, neuromuscular disorders, or aging $[1,2,5,9,11,12,14$, $15,27,53,54,59,61,102-105]$. Vallecillo-García and colleagues showed that the source of developmental ECM in limb muscles is a heterogeneous population of PDGFR $\alpha$-expressing progenitors called embryonic FAPs, closely resembling the population of adult stromal cells we have described, along with other groups $[1,2,6,23$, $24,26]$. These findings led to some confusion in the nomenclature, with some publications distinguishing between FAPs and fibroblasts, some using the term FAPs as better representing their predominant fibrogenic and adipogenic developmental potential, and some remaining faithful to the historical term fibroblast, which are also known for being heterogeneous and plastic cells. Here, we propose that these muscle-resident multipotent progenitors, whether called FAPs or fibroblasts, are the same cells.

From this point on, the term PDGFR $\alpha+$ FAPs will refer to muscle-resident $\mathrm{CT}$ mesenchymal progenitor with multilineage developmental properties. As discussed below, recent advances in single-cell RNA sequencing demonstrated that FAPs comprise multiple sub-populations, some of which could be bona fide differentiated cells with little developmental potential left $[16,48,62,106-109]$. This may create a problem with nomenclature diversity, speculation, and high cellular heterogeneity within the adult stromal lineage [110]. FAP heterogeneity is also known to increase following 
injury and disease, which also complicates their classification and nomenclature $[48,62,66,108,111]$.

The muscle community has historically described interstitial cells with MSC capability (i.e., fibrogenic, adipogenic, chondrogenic, and osteogenic potency). In addition to PDGFR $\alpha+$ cells, muscle-resident pericytes have also been proposed to be MSCs that have adapted to the specialized functions required by their adjacent vascular niche. However, although PDGFR $\alpha+$ FAPs behave as and present defined canonical MSC properties, FAPs are different from tissue-resident pericytic "MSCs." Indeed, pericytes' cell-surface profile is CD34-/CD45and CD146+ $[112,113]$. Remarkably, Bianco and colleagues revisited the MSC origins and differentiation potential using a broad set of human MSC-like cells (HLA class I, CD73, CD90, CD105, and CD146 positive cells). The authors showed that the cell surface phenotype of "MSCs" isolated from bone marrow, skeletal muscle, periosteum, and cord blood, although quite identical, did not reflect these cells' cell transcriptomic identity, function, and therefore, their differentiation properties. Thus, "MSCs" are separated from each other, as the authors defined it, by a developmental origin factor [113]. Notably, the authors also showed that CD146+ pericytes are not true MSCs in most of the analyzed tissues, with the possible exception of the bone marrow, where they inherently form bone and bone marrow stroma but lack chondrogenic potential in vivo or myogenic in vitro. On the contrary, in skeletal muscle, CD146+ perivascular pericytes are rather inherently myogenic than skeletogenic [113]. Remarkably, skeletal muscle pericytes are a distinct cell type from MuSCs (CD56+/CD146-) and CD34+/CD146+ endothelial cells that possess a latent myogenic gene signature and potential, and hence, muscle pericytes are committed myogenic progenitors $[113,114]$. These pivotal studies have challenged the loose and non-specific MSC nomenclature. However, further studies with lineage tracing and clonal assays are needed to deeply understand stromal cell dynamics in development, homeostasis, and injury and, therefore, to finally faithfully unify their markers, nomenclatures, and definitions.

The abundance of collagen, especially the most abundant protein in animals, type I collagen, determines the stiffness of mammalian tissues [115]. Notably, increased production and deposition of type I collagen fibrils are found after muscle damage. Several cell sources have been suggested as producers of collagen proteins. Using a murine model of increased of increased muscle fibrosis, Chapman et al. corroborated that at least three different muscle-resident cell populations express collagen I, among them PDGFR $\alpha+$ FAPs. However, muscle progenitors ( $\alpha$ 7-INTEGRIN) + and SCA- $1+$ cells also express the mRNA for this fibrillar matrix protein $[17,18]$.
These results further confirm our idea that muscle FAPs cannot be solely identified using collagen I reporter mice, but as previously suggested, we strongly recommend employing PDGFR $\alpha$ expression. Since most of the work related to FAPs biology refers to models of single, or repeated rounds of injury, we believe that further studies will likely uncover the role of PDGFR $\alpha+$ cells in atrophy-related pathologies such as aging-related sarcopenia, cachexia, myasthenia gravis, polytrauma, and neuromuscular disorders. Further research is needed to clarify the existence of subtle differences within stromal cells that might have functional impacts and consequences in muscle physiology, not only during maintenance but also in pathological and disease states.

\section{Multipotency of muscle-resident PDGFRa+ fibro- adipogenic progenitors}

In healthy adult muscles, we and others have demonstrated that PDGFR $\alpha+$ cells represent between 5-15\% of the total nuclei and $\sim 20-30 \%$ of the interstitial mononuclear cells at homeostasis $[11,12,106,107,116]$. Stromal PDGFR $\alpha+$ FAPs display MSC properties and can spontaneously differentiate into adipocytes (rounded, single-vacuole lipid-rich cells, perilipin + and peroxisome proliferator-activated receptor gamma+ (PPAR $\gamma)$ ), activated fibroblasts (long-shaped contractile cells with fibroblast-like morphology, $\alpha \mathrm{SMA}^{+}$(Acta2), and highly producing ECM cells), as well as chondrocytes/osteoblasts when bulk cultured, and in clonal assays in vitro and in vivo $[1,2,11-1315,50,51,59,104,117]$. Notably, HGFA, an injury-induced systemic cue, activates muscle FAPs, priming these cells to transition from quiescence into a cellular state with enhanced regenerative potential also known as $\mathrm{G}$ alert state [118]. In the following chapters, we discuss FAP multipotency (Fig. 2).

\section{Fibrogenic potential of PDGFRa+ FAPs}

When FAPs are cultured in vitro using standard growth media and $20 \%$ oxygen, a large proportion of them will spontaneously differentiate into activated fibroblasts with $\alpha \mathrm{SMA}^{+}$stress fibers $[1,11,12,15]$ (Fig. 2). This demonstrates that FAPs have intrinsic capabilities to differentiate, which is unleashed following their activation and makes in vitro studies easily feasible. However, the mechanisms regulating the fibrogenic potential of FAPs remain underexplored.

\section{Transforming growth factor-beta signaling}

One of the most studied signaling pathways in regulating the behavior and fate of muscle FAPs is the transforming growth factor-beta (TGF- $\beta$ ) signaling pathway. The TGF- $\beta$ sub-family of cytokines (TGF- $\beta 1$, TGF- $\beta 2$, and TGF- $\beta 3$ ) are secreted proteins that participate in celland tissue-specific biological processes such as wound 


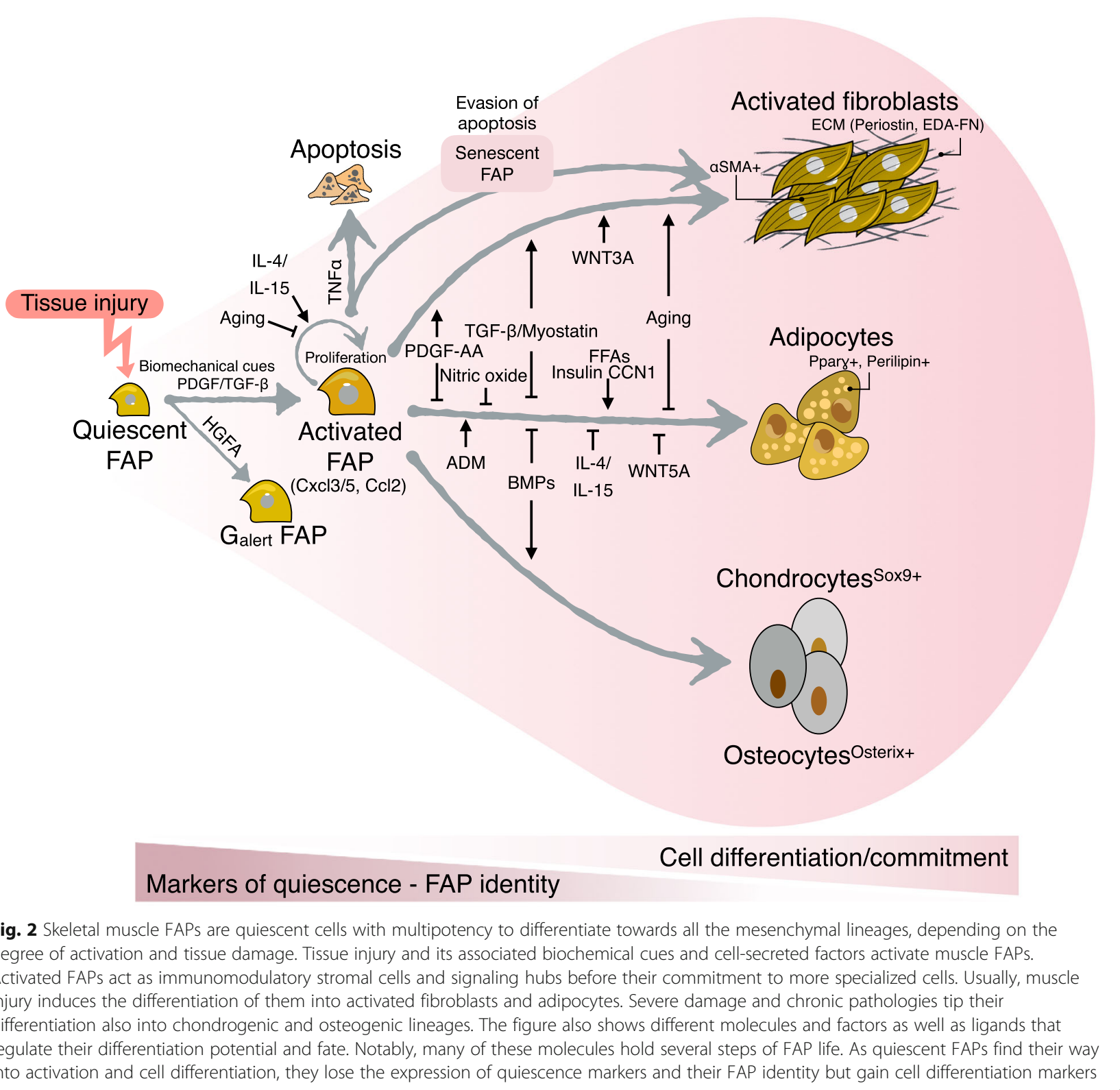

healing, angiogenesis, immune regulation, apoptosis, tumorigenesis, and proliferation. In pathological conditions, they strongly associate with tissue damage, dysfunction, and fibrosis and are notably mis-expressed (Burks \& Cohn, $[119,120])$. The complexity of the TGF$\beta$ pathway is exemplified by its pleiotropic effects, inducing growth arrest in some cell types but promoting the proliferation of others $[121,122]$. TGF- $\beta$ enhances the proliferation and differentiation of several cell types, including stromal cells (for review, see [123, 124].

When secreted, TGF- $\beta$ associates non-covalently to a large complex consisting of the latency-associated peptide (LAP) and latent TGF- $\beta$-binding protein (LTBP) proteins [125]. Extracellular TGF- $\beta$ is activated after its release from the LAP-LTBP complex, which can occur via proteolytic rupture or through ECM-cell forces generated by cell traction via the integrin complexes [126129]. After release, TGF- $\beta$ binds to its heteromeric serine/threonine kinase type 1 and 2 receptors [TGFBR1/ALK5 and TGFBR2, respectively], and TGFBR3 (also known as betaglycan) co-receptor on the cell surface of the target cell. Of interest, while TGF$\beta$ family ligands can bind TGFBR3, this receptor does not have signaling activity on its own, but it modifies the affinity of TGFBR1 and 2 to TGF- $\beta$ ligands [130]. Indeed, TGFBR3 acts as a co-receptor, amplifying TGF- $\beta$ signaling activation [131]. TGFBR3 also binds other TGF- $\beta$-family ligands such as ACTIVINS, INHIBINS, 
and bone morphogenetic proteins (BMPs), which we know are primordial proteins for ECM remodeling in skeletal muscle $[132,133]$. This co-receptor can also be soluble (by a mechanism called shedding [134]) and could, in some cases, act as an inhibitor of the TGF- $\beta$ signaling by sequestration of its various ligands [131, 135]. Nevertheless, the function of TGFBR3 in FAP or mesenchymal progenitor behavior has not been studied yet. Its modulation could be a powerful tool as TGFBR3 misexpression is associated with cancer and metastasis [136], in which ECM remodeling is known to be highly active.

Then TGF- $\beta$ canonical downstream effectors SMAD2 and SMAD3 (R-SMADs) are phosphorylated throughout TGFBR1/ALK5 kinase activity and form a cytoplasmic heteromeric complex with SMAD4 (co-SMAD) [121, 122]. This ternary protein complex translocates to the nucleus where it recognizes SMAD-binding elements (SBE) in the DNA to regulate the expression of diverse target genes [123, 137]. In parallel, SMAD6 and SMAD7 act as inhibitors (also called I-SMADs). Their model of action can be various (via TGFBR1 or SMAD4), but their activation is often a result of a negative feedback loop aiming to downregulate the TGF- $\beta$ or the BMP signaling pathway [138-140]. TGF- $\beta$ also activates non-canonical downstream signaling pathways such as ABL, PI3K-AKT, RHO, TAK1, ERK1/2, JNK, and p38-MAPK [124, 141]. In vitro and in vivo experiments suggest that both canonical and non-canonical TGF- $\beta$ pathways are involved in fibroblast proliferation and myofibroblast differentiation, and thereby modulate TGF- $\beta$-induced fibrosis and ECM remodeling [11, 12, 120, 126, 128, 141-143]. However, the specific role of TGF- $\beta$ canonical and non-canonical pathways in regulating muscle-resident PDGFR $\alpha+$ FAP plasticity and fate remains underexplored.

In response to muscle injury, TGF- $\beta$ is produced and secreted by macrophages, FAPs, and regenerating myofibers $[11,12,59,144,145]$. Muscle FAPs express the three TGF- $\beta$ isoforms (TGF- $\beta 1$, TGF- $\beta 2$, and TGF- $\beta 3$ ) and TGF- $\beta$ receptors (TGFBR1, TGFBR2, and TGFBR3) $[11,12]$. TGF- $\beta$ ligands through TGFBRs induce FAPmyofibroblast differentiation and ECM production [11, $12,144,146]$. In addition, TGF- $\beta$ inhibits the adipogenic priming of muscle FAPs [11], and is pro-mitogenic, and hence, stimulates the proliferation of PDGFR $\alpha+$ FAPs $[11,12,59,144]$ (Fig. 2). TGF- $\beta$ signaling pathway activation also seems to be required for FAP survival since the in vivo treatment of mice with SB431542-a selective and potent ALK4, ALK5, and ALK7 receptor inhibitorreduced the number of expanded FAPs following rotator cuff tear injury [147] (Table 3). Remarkably, we also showed that TGFBR1 and the $\mathrm{p} 38$-MAPK protein are responsible for TGF- $\beta$-mediated downregulation of PDGF $\mathrm{R} \alpha$ [11], associated with a decrease in TCFL2 expression in vitro and in vivo [28]. Thus, as these cells activate, proliferate, and differentiate they lose or reduce the expression of their progenitor state markers (Fig. 2).

\section{Wnt/ $\beta$-catenin signaling}

The Wnt/ $\beta$-catenin pathway relies on the binding of Wnt ligands to Frizzled receptors and the co-receptors LRP5 and LRP6 at the cell surface to initiate a cascade that regulates the intracellular proteostasis of $\beta$-catenin (for recent reviews about the $\mathrm{Wnt} / \beta$-catenin signaling see $[156,157]$. At steady state, the $\beta$-catenin pool that is not participating in cell adhesion is bound to a destruction complex, where it becomes phosphorylated and targeted for degradation in a process mediated by the ubiquitin-proteasome system (UPS) [158]. The Wnt ligand-mediated destabilization of the $\beta$-catenin destruction complex leads to the accumulation of activated $\beta$ catenin (unphosphorylated). Accumulated cytoplasmatic $\beta$-catenin subsequently translocates to the nucleus and associates with DNA-binding T-cell factor (TCF) or lymphoid enhancer factor (LEF)-TCF/LEF- transcription factors (TFs) [159]. The binding of $\beta$-catenin and TCF/LEF recruits transcriptional partners and chromatin remodeling complexes to regulate the expression of TCF/LEF target genes [160, 161].

Despite the increasing knowledge about the Wnt signaling pathway, the participation of Wnt proteins and signaling in modulating FAP fate has not been investigated until recently. Skeletal muscle SCA-1+ cells (FAPs) are abundant in the muscles of the $m d x$ mice (model of the Duchenne Muscular Dystrophy (DMD)), and WNT3a treatment promotes their proliferation and collagen expression both in vitro and in vivo [162]. Interestingly, the treatment of dystrophic mice with DKK1 (Dickkopf 1, a WNT inhibitor) reduced $\beta$-catenin protein levels and muscle fibrosis [162]. On the other hand, increased canonical Wnt/ $\beta$-catenin signaling regulates satellite cell fate and fibrogenic commitment via crosstalk with TGF- $\beta 2$ in dystrophic $m d x$ muscles [163]. Accordingly, we also observed increased $\beta$-catenin protein levels upon acute glycerol muscle injury [28]. Xiang and colleagues showed that the conditional genetic loss of $\beta$ catenin in heart fibroblast (Transcription factor 21 $(\mathrm{TCF} 21)+$ cells) and activated fibroblasts and myofibroblasts (Periostin+) lineages reduces fibrosis and ameliorates cardiac hypertrophy induced by pressure overload [164]. In agreement, the sole transgenic overexpression of canonical WNT10B is sufficient to induce fibrosis in vivo [165]. Overall, the $\mathrm{Wnt} / \beta$-catenin pathway regulates the expression of several ECM genes in fibroblasts from different tissues and organs following injury and disease $[28,164-166]$.

The outcomes of Wnt/B-catenin signaling depend on the TCF/LEF TFs. However, the potential roles of them 
Table 3 Summary of drug strategies to target muscle fibro-adipogenic progenitor differentiation and fate

\begin{tabular}{|c|c|c|c|c|c|c|c|}
\hline Therapy & Target & $\begin{array}{l}\text { Cell } \\
\text { survival }\end{array}$ & Proliferation & $\begin{array}{l}\text { Cell death/ } \\
\text { apoptosis }\end{array}$ & Fibrogenesis & Adipogenesis & References \\
\hline AG1296 & $\begin{array}{l}\text { PDGFR kinase activity } \\
\text { inhibitor }\end{array}$ & $\begin{array}{l}\text { Not } \\
\text { evaluated }\end{array}$ & Reduced? & Not evaluated & Reduced & Not evaluated & [11] \\
\hline AICAR & AMPK activator & Reduced & $\begin{array}{l}\text { Not } \\
\text { evaluated }\end{array}$ & Induced & $\begin{array}{l}\text { Not } \\
\text { evaluated }\end{array}$ & Reduced & [148] \\
\hline Azathioprine & Immunosuppressant & $\begin{array}{l}\text { Not } \\
\text { affected }\end{array}$ & Reduced & Not affected & Not affected & Reduced & [149] \\
\hline Batimastat & $\begin{array}{l}\text { MMPs inhibitor } \\
\text { (including MMP14) }\end{array}$ & $\begin{array}{l}\text { Not } \\
\text { affected }\end{array}$ & Not affected & Not affected & Not affected & Reduced & [14] [104] \\
\hline BMS493 & $\begin{array}{l}\text { Pan-retinoic acid } \\
\text { receptor (RAR) inverse } \\
\text { agonist }\end{array}$ & $\begin{array}{l}\text { Not } \\
\text { evaluated }\end{array}$ & Reduced & Not evaluated & Reduced & $\begin{array}{l}\text { Induced } \\
\text { spontaneous } \\
\text { differentiation }\end{array}$ & [69] \\
\hline Dexamethasone & $\begin{array}{l}\text { Glucocorticoid } \\
\text { receptor }\end{array}$ & Induced & Induced & Not affected & $\begin{array}{l}\text { Not } \\
\text { evaluated }\end{array}$ & Induced & [150] \\
\hline $\begin{array}{l}\text { HDAC inhibitors }{ }^{a} \text { (TSA and } \\
\text { Pracinostat) }\end{array}$ & HDACs & $\begin{array}{l}\text { Not } \\
\text { evaluated }\end{array}$ & $\begin{array}{l}\text { Not } \\
\text { evaluated }\end{array}$ & Not evaluated & Reduced & Reduced & $\begin{array}{l}{[28][151]} \\
{[152] ;}\end{array}$ \\
\hline $\begin{array}{l}\text { LY2090314 \& other GSK } \\
\text { inhibitors }\end{array}$ & GSK3 inhibitors & $\begin{array}{l}\text { Slightly } \\
\text { decreased }\end{array}$ & Not affected & Not affected & Mixed results & Reduced & [153] \\
\hline Metformin & AMPK activator & $\begin{array}{l}\text { Not } \\
\text { evaluated }\end{array}$ & Reduced & Not evaluated & $\begin{array}{l}\text { Not } \\
\text { evaluated }\end{array}$ & Reduced & [16] \\
\hline Molsidomine & NO donating molecule & Reduced? & Reduced? & Not evaluated & Reduced & Reduced & [154] \\
\hline Promethazine hydrochloride & $\mathrm{H} 1$ histamine receptor & $\begin{array}{l}\text { Not } \\
\text { affected }\end{array}$ & Not affected & Not affected & $\begin{array}{l}\text { Not } \\
\text { evaluated }\end{array}$ & Reduced & [72] \\
\hline SB525334/SB431542 & $\begin{array}{l}\text { TGFBR kinase activity } \\
\text { inhibitor }\end{array}$ & Reduced & Reduced & $\begin{array}{l}\text { Induced after } \\
\text { long } \\
\text { treatment }\end{array}$ & Reduced & Not evaluated & {$[11,12][147]$} \\
\hline $\begin{array}{l}\text { TKls (imatinib, nilotinib, } \\
\text { crenolanib, sorafenib, and } \\
\text { masitinib) }\end{array}$ & $\begin{array}{l}\text { Abl, PDGFRs, Kit, DDRs, } \\
\text { p38 }\end{array}$ & Reduced & Reduced & Induced & Reduced & $\begin{array}{l}\text { Reduced and/or } \\
\text { Induced }\end{array}$ & $\begin{array}{l}{[11,12] ; \text { b }[16] ;} \\
{[59] ;[155] ;} \\
{[146] ;}\end{array}$ \\
\hline
\end{tabular}

${ }^{a}$ HDACs-mediated effects on FAP fate are seen only in young mdx but not aged mdx mice

${ }^{b}[16]$ reported that imatinib enhances the amount of perilipin+ FAP-derived adipocytes in vitro

in muscle FAPs are underexplored. These TFs recognize TCF/LEF-binding elements and regulatory regions of target genes to regulate gene expression. In this context, we showed the expression of the four Wnt TCF/LEF members in MSC and fibroblast cell lines, as well as tissue-resident FAPs from skeletal muscle and cardiac tissues [28]. We observed that Tcf7l2 and Tcf7l1 were the two most highly expressed members, whereas the fibroblast lineage, including FAPs, express Tcf7 and Lef1 at lower levels. Moreover, treatment with TGF- $\beta$ decreases both the mRNA and protein levels of TCF7L2 in PDGFR $\alpha+$ cells. We described that this regulatory mechanism requires the transcriptional regulation activity of histone deacetylases (HDACs) and the participation of the UPS [28].

Interestingly, TGF- $\beta$ activates the canonical Wnt $/ \beta$-catenin cascade and induces nuclear accumulation of $\beta$ catenin, which in turn reduced the expression of the WNT inhibitor DKK1 [165]. In agreement with our most recent results showing that TGF- $\beta$ reduces the expression of several TCF7L2 target genes, whereas it promotes the expression of ECM remodeling genes in idiopathic pulmonary fibrosis and heart fibroblasts [28]. Hence, our work confirms the cross-talk between the Wnt and TGF- $\beta$ pathways that controls the fate of PDGFR $\alpha+$ cells and potentially fibrosis (Table 3 ). In summary, the Wnt cascade modulates TGF- $\beta$-mediated effects in fibroblasts, and vice versa [28, 167-169].

\section{Platelet-derived growth factor signaling}

The platelet-derived growth factor (PDGF) signaling pathway regulates not only vascular development and angiogenesis [170] but also plays crucial roles during development, stem cell fate, migration, and proliferation. PDGF receptors (PDGFRs) are the cell membranebound tyrosine kinase receptors for PDGF ligands [171174]. PDGFs were initially described as serum-derived mitogens essential for fibroblast and smooth muscle cell growth $[175,176]$. PDGFs ligands are four gene products consisting of five dimeric isoforms: the homodimers PDGF-AA, PDGF-BB, PDGF-CC, PDGF-DD, and the PDGF-AB heterodimer [177]. PDGFs are known for being released from $\alpha$-granules of platelets and are potent chemoattractants and mitogens for cells of mesenchymal 
origin [178]. However, several other cell types express and secrete these ligands, such as inflammatory cells (e.g., macrophages) and fibroblasts [179]. Posttranslational proteolytic processing of PDGFs is necessary for their activation. It occurs extracellularly for PDGF-C and PDGF-D but intracellularly for PDGF-A, PDGF-B, and PDGF-AB [178, 179]. A biologically active PDGF ligand is a dimer of two single PDGF chains, which binds one PDGFR.

PDGFRs genes (PDGFRA and PDGFRB) encode single-pass transmembrane receptors with an extracellular portion of five immunoglobulin-like domains, a transmembrane segment, a juxtamembrane segment, a tyrosine kinase domain, and a carboxy-terminal tail [180]. PDGFRs are monomeric before exposure to PDGF [181]. Its ligand binding-induced dimerization causes their activation, and therefore, later PDGFR derepression and activation of the receptor's tyrosine kinase activity [180, 182, 183]. Three known functional dimer forms of the receptors exist. They consist of the PDGFR $\alpha / \alpha$ and PDGFR $\beta / \beta$ homodimers and the PDGF $R \alpha / \beta$ heterodimer $[179,180]$. PDGF-AA, PDGF-AB, PDGF-BB, and PDGF-CC promote PDGFR $\alpha / \alpha$ homodimer formation, PDGF-BB, PDGF-CC, PDGF-DD, and PDGF-AB promote PDGFR $\alpha / \beta$ heterodimer assembly. PDGFR $\beta / \beta$ homodimer can only be induced by PDGFBB and PDGF-DD isoforms [177, 178, 180]. Although the precise role of PDGF and its receptors in vivo in muscle-resident FAPs is unknown, PDGF signaling seems to regulate FAP survival, activation, proliferation, migration, and fate. In this review, we focused on PDGF ligands and PDGFR $\alpha$ in skeletal muscle health and pathophysiology.

Treatment of ex vivo FAPs with PDGF-AA and PDGFBB ligands activates the PDGF cascade inducing FAP activation and proliferation (Fig. 2) [11, 53]. In addition, upregulated expression of ECM genes and activated downstream ERK1/2, PI3K-AKT, and SMAD2/3 signaling pathways is observed in ex vivo FAPs in response to PDGF-AA treatment $[53,184]$. By utilizing a pharmacological inhibitor of PDGFR signaling, Mendias and colleagues showed that PDGFR signaling modulates muscle ECM remodeling and angiogenesis upon synergist ablation surgery to induce postnatal muscle growth or hypertrophy [185]. In addition, the treatment with PDGF-AA induces the phosphorylation of PDGFR $\alpha$ and the proliferation of PDGFR $\alpha+$ cells (Fig. 2) [53]. The authors also suggested, using pharmacological inhibitors, that both PI3K-Akt and MEK2-MAPK signaling pathways are necessary for PDGFR $\alpha$-induced proliferation $[53,54]$. However, persistent PDGF ligand exposure and enhanced PDGFR $\alpha$ signaling levels can cause pathological muscle fibrosis $[53,54,155,184]$. We have recently shown that PDGF-BB treatment activates proliferative and differentiation-related downstream signaling pathways such as PI3K-AKT, ERK1/2, p38MAPK, and STAT3 in PDGFR $\alpha$ expressing cells [11, 12]. Recently, Farup et al. showed that PDGF-AA treatment increases the expression of collagen type I in FAPs, whereas it reduces their adipogenic differentiation (Fig. 2). Notably, the PDGF-AA-mediated fibrogenic fate of FAPs associates with a metabolic switch that promotes enhanced glucose consumption [16]. Hence, PDGF signaling could regulate the potency and fate of skeletal muscle FAPs (Fig. 2).

In the heart, Asli et al. showed that PDGF-AB treatment promotes colony formation and self-renewal of cardiac fibroblast, whereas the PDGFR inhibitor, AG1296, suppressed these activities [186]. Interestingly, activated PDGFR $\alpha$ H2BEGFP-mid fibroblasts formed at the expense of resting PDGFR $\alpha$ H2BEGFP-high fibroblasts $[73,186]$. These results are in agreement with our recent findings where the expression of PDGFR $\alpha$ changes dynamically during muscle regeneration and repair [11]. Moreover, in vivo PDGF-AB treatment of uninjured hearts did not cause fibroblast activation; however, it increased the number of PDGFR $\alpha$ H2BEGFPmid fibroblasts after myocardial infarction [186]. Therefore, PDGF-AB isoform targets tissue-resident fibroblasts by increasing the activated fibroblast pool after injury. Interestingly, genetic loss of Pdgfra in the resident cardiac fibroblast lineage (TCF21+ cells) results in an overall reduction in the fibroblast population in adult hearts, demonstrating that PDGFR $\alpha$ regulates fibroblast maintenance and homeostasis [187]. Consistently, lineagespecific deletion of Pdgfra in tubulin polymerizationpromoting protein family member 3 expressing cell population (Tppp3+ tendon stem cells) caused impaired tendon regeneration, and therefore, corroborates the cell requirements of PDGFR $\alpha$ signaling for proper tendon healing [188]. Remarkably, the passaging of plastic adherent FAPs obtained from muscles reduces the protein levels of PDGFR $\alpha$, which associates with their differentiation [12]. Thus, cellular PDGFR $\alpha$ bioavailability may be a modulating factor in PDGF-mediated responses of FAP lineage during survival, fate decisions, and damageassociated behaviors.

\section{Adipogenic potential of PDGFRa+ FAP cells}

Infiltration and deposition of fatty adipose tissue are hallmarks of several skeletal muscle pathologies. However, the cellular and molecular mechanisms underlying fatty infiltration of muscles have not been extensively investigated compared with the ever-growing research in muscle fibrosis. A better understanding of such a discrete fat compartment between myofibers and fascia, also called intra/intermuscular adipose tissue (IMAT), 
may allow for the targeting of these adipogenic progenitors to increase muscle regeneration and repair.

The lack of reliable cell-specific markers for fat precursor cells has been the main limitation of studying IMAT. As described above, the studies of Joe et al. and Uezumi et al. helped to clarify many aspects of the muscle adipogenic precursor cells. One major focus of these approaches was determining whether IMATassociated adipocytes were in vivo derived from preexistent muscle-resident PDGFR $\alpha+$ cells, other muscleresident cells, or circulating cells. The work led by Liu et al. in murine skeletal muscle is a classic example of these efforts. The authors suggested that IMAT derives from a lineage of cells not expressing Pax3 (i.e., nonmyogenic). They also showed that the genetic ablation of intramuscular adipogenic progenitors based on $A p 2$ (also known as fatty acid-binding protein 4 (FABP4)) expression leads to impaired skeletal muscle regeneration, suggesting for the first time that damage-induced fatty tissue may support efficient regeneration upon acute injury [189]. However, AP2/FABP4 expression is commonly thought to be restricted to committed or differentiated adipocytes than progenitor cells [190], questioning the interpretation of the results. Marinkovic et al. [111] showed that Notch signaling is a pivotal pathway regulating FAP adipogenesis in wild-type cells and that dystrophic FAPs are insensitive to Notchmediated adipogenic inhibition compared with acute injury-derived FAPs [111]. Hence, these results demonstrate that wild-type and dystrophic muscle PDGFR $\alpha+$ FAPs are in different functional states, which influences their fate and responsiveness to extracellular cues, as previously suggested [62].

Human PDGFR $\alpha+$ FAPs exist in healthy and DMD pathological muscles, being bona fide counterparts of the PDGFR $\alpha+$ cells found in mouse muscles $[16,50,51$, 53, 54, 109]. Remarkably, FACS-isolated human FAPs (CD15+/PDGFR $\alpha+/ C D 56-)$ differentiate towards fully mature adipocytes, phenocopying the in vitro differentiation kinetic and potential of adipose stromal cells obtained from subcutaneous adipose tissue depots [51]. Moreover, when transplanted into a glycerol-damaged muscle (an injury model that promotes adipogenesis) [191, 192], murine FAPs readily differentiate into adipocytes. In concordance to the in vitro report of Liu and colleagues using mouse muscle samples, Arrighi et al. also showed that FAP-derived adipocytes from human muscle biopsies are white rather than beige/brown fat cells. In contrast, Gorski et al. showed increased expression of UCP1, a brown/beige fat cell marker [193], in muscle as well as in FAP cultures following induction of IMAT by glycerol injection [194]. Throughout the body, white fat cells store energy in large, often single, oily droplets. Obesity causes these white adipose tissue cells to multiply and hypertrophy $[195,196]$. On the other hand, brown fat cells are equipped with smaller droplets and large mitochondria concentration, giving the tissue its chestnut hue. Hence, in brown adipose tissue, mitochondria produce heat using these fatty droplets, a process also known as thermogenesis [197]. The role of FAP-derived fat cells, whether brown/beige or white, in skeletal muscle health, regeneration, and disease is unknown.

Perhaps the most serious disadvantage of these studies is that they do not directly address the in vivo adipogenic differentiation potential of adult PDGFR $\alpha+$ FAPs. The definitive proof that muscle PDGFR $\alpha+$ cells are the main, if not the only, source of injury-induced adipocytes came from lineage tracing experiments using Pdgfra ${ }^{\text {CreERT }}:$ Rosa $26^{\text {EYFP }}$ transgenic mice [14]. The authors demonstrated that seven days after acute intramuscular injury, a large proportion of perilipin+ adipocytes derived from PDGFR $\alpha+$ FAPs, indicating that PDGFR $\alpha$ expressing progenitors are the major source of damageinduced fat cells in normal muscle regeneration and in muscular dystrophy. Indeed, using similar lineage tracing strategies we have demonstrated that cardiac PDGFR $\alpha+$ FAPs can cause fibrofatty infiltration within the myocardium in an arrhythmogenic cardiomyopathy mouse model driven by the conditional deletion of the quiescence-associated factor Hic1 in heart FAPs [73].

Intriguingly, PDGFR $\alpha+$ FAPs are ciliated cells and thus possess primary cilium. Conditional deletion of a gene required for ciliogenesis, Ift88, in FAPs impaired the injury-induced formation of adipocytes [14]. Mechanistically, the cilia-dependent modulation of FAP adipogenesis involves the participation of Sonic Hedgehog (SHH) signaling, which is repressed in the absence of cilia. Indeed, constitutive activation of the Shh-pathway via genetic deletion of the repressor Ptch1 was sufficient to block adipocytes' generation following injury [14]. Remarkably, elimination of the primary cilium in PDGF $R \alpha+$ FAPs led to enhanced regeneration of myofibers by reducing fatty degeneration of dystrophic muscles, which was also associated with increased myofiber size. The authors also showed that tissue inhibitor of metalloproteinase 3 (TIMP3), an ECM modifier, inhibits adipocyte formation by muscle PDGFR $\alpha+$ progenitors. Interestingly, aiming to mimic TIMP3 activity, the authors utilized batimastat and showed that the treatment with this pharmacological inhibitor of metalloproteinases prevented injury-induced adipogenesis in vivo [14] (Table 3).

In a different study, Jaiswal and colleagues showed that the treatment with Batimastat prevented FAP spontaneous adipogenesis and reduced fat in dysferlinopathic muscle of dysferlin-deficient (B6A/J) mice [104]. Hence, the authors suggested that the accumulation and 
adipogenic differentiation of FAP are critical contributors to limb-girdle muscular dystrophy type 2B. Surprisingly, the authors observed no changes in either FAP accumulation, proliferation, or fibrosis as a result of batimastat treatment (Table 3). Nevertheless, the batimastat's off-targets on other tissue-resident cells such as MuSCs, myofibers, endothelial cells, pericytes, or infiltrating CD45+ cells have not been evaluated yet. Altogether, these findings suggest novel strategies to combat fatty degeneration of chronically damaged muscles by targeting the adipogenic conversion of PDGFR $\alpha$ expressing FAPs to inhibit the deposition of injury- and disease-induced intramuscular fat.

To date, there is not a single clinically approved drug used to prevent IMAT accumulation in muscle disease. However, significant pre-clinical advances have been made. In vivo treatment of $m d x$ mice with molsidomine-a nitric oxide (NO) donating molecule-reduced muscle pathology, IMAT accumulation, and fibrosis [154]. These improvements were at least in part mediated by the inhibition of NO-mediated FAP adipogenesis (Table 3). Hence, altered synthesis of NO, a typical finding in DMD, could contribute to enhanced fat deposition. On the search for adipogenic inhibitors, Uezumi and colleagues found that promethazine hydrochloride inhibits, through binding to the $\mathrm{H} 1$ histamine receptor, the in vitro and in vivo formation of ectopic adipocytes derived from PDGFR $\alpha+$ lineage cells in the muscle [72] (Table 3). Promethazine hydrochloride is a firstgeneration antagonist of the $\mathrm{H} 1$ histamine receptor, and therefore, this family of drugs emerge as attractive novel therapeutics against ectopic fat formation in muscle pathologies.

Histone deacetylation leads to the repression of gene expression, and histone deacetylase inhibitors (HDACi, like trichostatin A) provide an exciting means to treat DMD. HDACi have been used in both pre-clinical and clinical studies to improve muscle regeneration and repair in DMD [151, 198-200]. As HDACi treatment inhibits fibro-fatty differentiation of PDGFR $\alpha+$ FAPs, it reduces the dystrophic pathology through increasing muscle regeneration [151]. Remarkably, in dystrophic FAPs, an HDAC-myomiR-BAF60 molecular network regulates FAP fate, and old FAPs become resistant to HDACi-induced chromatin remodeling compared with young FAPs [201]. Also, HDACi restore the dystrophicmediated loss of intercellular communication between PDGFR $\alpha+$ FAPs and myogenic progenitors required for proper muscle regeneration [151], and as recently suggested through an extracellular vesicle-mediated transfer of miRNAs [200]. Interestingly, aging and DMD disease progression limit HDACi-mediated effects [151], which suggests that aging affects the fate of FAPs, as recently detailed by Lukjanenko and colleagues [5]. Recently,
Feeley and colleagues showed that rotator cuff tears enhanced HDAC activity in FAPs and trichostatin A inhibited it. HDAC inhibition prevented FAP-mediated fatty infiltration in supraspinatus muscles. Also, trichostatin A regulates muscle FAP adipogenesis by promoting FAP browning (Table 3) [152].

These studies demonstrated that HDACs-mediated pharmacological intervention might counter DMD progression and chronic muscle injury by increasing regeneration by inhibiting fibro-fatty degeneration while favoring the interplay and communication between FAPs and myogenic progenitors. Recently, we have shown that two well-characterized pan-HDACi reduce TGF- $\beta$ induced ECM gene expression and also block TGF- $\beta$ mediated downregulation of $T c f 7 l 2$ expression [28]. Mechanistically, histone deacetylase inhibitors modulate TGF- $\beta$-mediated changes in the expression of TCF7L2 transcription factor target genes of the Wnt pathway [28]. Further investigations should unravel the mechanism by which HDACs regulate the fate of FAPs and how could this be used to target muscle-associated diseases.

In a recent study, Reggio and colleagues used a large drug library screen with pharmacological approaches to demonstrate that the inhibition of the cytoplasmic signaling protein, glycogen synthase kinase 3 (GSK3), reduces PDGFR $\alpha+$ FAP adipogenesis in vitro, while also repressing muscle glycerol-induced fatty degeneration [153] (Table 3). GSK3 is composed of 2 isoforms ( $\alpha$ and $\beta$ ) and is part of the destruction complex of $\beta$-catenin, which we showed earlier to play a modulatory role in FAP fate (see the "Wnt/ $\beta$ signaling" section). Mechanistically, the authors suggested that UPS-targeted $\beta$ catenin degradation causes an imbalance in the adipogenic fate of dystrophic $m d x$ FAPs. The authors also exploited single-cell data and in silico modeling to show that PDGFR $\alpha+$ FAPs compose the core of the stromal cells in the muscle cell niche by expressing Wnt components and also for being the primary source of Wnt ligands. FAPs seem to actively communicate with endothelial cells, tenocytes, and MuSCs through the production of Wnt ligands. Among the Wnt ligands, they observed that dystrophic FAPs downregulate Wnt5a expression compared with wild-type cells. Moreover, WNT5a treatment reduced FAP-induced adipogenesis in vitro by repressing PPAR $\gamma$ expression throughout the activation of $\beta$-catenin, suggesting that the Wnt signaling modulates the adipogenic commitment of FAPs in dystrophic muscles (Fig. 2).

On the other hand, Zhao and colleagues recently described that the supplementation of retinoic acid (RA) enhances the proliferation of FAPs at the expense of inhibiting their adipogenic and fibrogenic differentiation [69]. Additionally, treatment of isolated FAPs with a pan-retinoic acid receptor antagonist, BMS493, blocked 
the RA-mediated effects. Notably, the authors also showed that RA treatment rescued obesity-impaired skeletal muscle regeneration. These findings showed a FAP-type specific effect of RA signaling that regulates skeletal muscle regeneration and repair by means of preserving their progenitor state. Taken together, these findings suggest a novel potential retinoic acid-based strategy to combat chronic skeletal muscle fibro-fatty degeneration of obese patients.

On the contrary, several factors positively regulate muscle FAP adipogenesis. For instance, the matricellular protein $\mathrm{CCN}$ family member 1 (CCN1/CYR61) is elevated in the serum and sarcopenic muscles of a murine model of chronic kidney disease and induces FAP adipogenesis [202]. In vivo treatment of mice with the glucocorticoid dexamethasone enhanced IMAT deposition following acute injury (Dong et al., 2014 [150]). Dexamethasone also induces FAP proliferation while increasing their adipogenesis, possibly involving the reduction of IL-4 expression (Dong et al., 2014 [150]). Remarkably, IL-4 administration reduces dexamethasone-induced FAP-derived adipocyte formation, suggesting a novel therapeutic use of IL-4 to reduce IMAT accumulation due to glucocorticoid use in DMD patients (Fig. 2). Perpetuini et al. showed that the glucocorticoid-related molecules, dexamethasone, and budesonide, inhibited the insulin-induced adipocyte formation from $\mathrm{mdx}$ derived FAPs. However, both drugs have a proadipogenic impact when the adipogenic mix contains factors that increase the concentration of cyclic AMP. The authors also showed that, only in anti-adipogenic conditions, budesonide suppresses the expression of Pparg, a master adipogenic regulator, via the glucocorticoid-induced-leucine-zipper (GILZ/TSC22D3), and the glucocorticoid antagonist mifepristone alleviates such inhibitory effect [203] (Table 3). This study may shed light on some of the mechanisms underlying the use of glucocorticoids in DMD patients under this kind of treatment. The use of glucocorticoids to treat DMD patients is so far the most common treatment available to delay muscle necrosis and degeneration up to date [204-206]. Finally, the same group, using a similar chemical library-based approach, identified an immunosuppressant drug, azathioprine, that negatively perturbs the intrinsic adipogenic fate, also via PPAR $\gamma$ repression, of wild type and mdx PDGFR $\alpha+$ FAPs (Table 3).

On the other hand, we recently showed that TGF- $\beta$ treatment negatively affects FAP differentiation to adipocytes while inducing FAP-to-myofibroblast commitment (Fig. 2). TGF- $\beta 1$ impairs basal PDGFR $\alpha+$ FAP differentiation into the adipogenic lineage, by reducing the steady-state percentage of adipocytes but increasing the number of myofibroblasts [11, 207]. Mechanistically, TGF- $\beta$ treatment reduces the expression of Ppary and
Adiponectin in skeletal muscle FAPs [11, 12]. We also showed that the adipogenic differentiation of FAPs represses the expression of PDGFR $\alpha$ [11]. Taken together, these studies demonstrate that IMAT-associated adipocytes can derive from pre-existent muscle-resident fibroadipogenic progenitors.

\section{Osteogenic differentiation of PDGFRa+ FAP cells}

Muscle PDGFR $\alpha+$ FAPs have osteogenic potential in vitro [2] and when transplanted can successfully engraft and form calcification-rich structures using an in vivo heterotopic ossification (HO) model [208]. HO is a musculoskeletal disorder distinguished by the pathologic formation of extraskeletal bone in muscle, tendon, ligaments, and fascia [209]. BMP2 promotes intramuscular $\mathrm{HO}$ regardless of damage; however, BMP9-induced $\mathrm{HO}$ requires skeletal muscle injury [210] (Fig. 2). The authors described that intramuscular $\mathrm{HO}$ might involve a population of Lin-SCA-1+ cells-likely FAPs [210]. Moreover, $\mathrm{Lin}^{-} / \mathrm{TIE} 2+/ \mathrm{PDGFR} \alpha+$ progenitors respond to BMP2-stimulated osteogenic commitment and contribute to $\mathrm{HO}$ in mice [211]. Additionally, musclederived MSCs contribute to fracture repair in a tumor necrosis factor-alpha (TNF $\alpha$ ) dependent manner [212]. The above findings are consistent with a recent study of Goldhamer's group, where the authors employed and characterized a transgenic mouse model that recapitulates a rare autosomal-dominant disorder called fibrodysplasia ossificans progressiva (FOP), which results from a single activating mutation in $A C V R 1$; the type I BMP receptor also known as ACVR1/ALK2. The Tie2driven expression of the mutation Acvr1 R206H is sufficient to phenocopy the spectrum of $\mathrm{HO}$ observed in FOP patients [60]. Moreover, they also showed that intramuscular transplantation of mutant Acvr1R206H/+ FAPs into immunodeficient mice resulted in the formation of $\mathrm{HO}$ in an Activin A-dependent fashion. Overall, these data established TIE2+/SCA-1+/PDGFR $\alpha+$ FAPs as the predominant cell-of-origin and driver of pathological HO. However, it has been suggested that TIE2 is a nonspecific marker for a subset of PDGFR $\alpha+$ cells since its expression overlaps with other cell populations like endothelial cells, MuSCs, and subsets of hematopoietic cells $[2,213,214]$. Hence, the precise mechanisms and the populations of cells involved in the formation and remodeling of $\mathrm{HO}$ remained unknown until then. We recently took advantage of a novel PDGF $\mathrm{R} \alpha$ lineage tracing reporter mouse (Pdgfr $\alpha$-CreERT2TdTomato) to further explore the cellular source of muscle ossification [13]. Using a model of BMP2stimulated intramuscular $\mathrm{HO}$, we showed that a large proportion $(\sim 80 \%)$ of differentiated osteogenic cells were TdTomato+ after 21 days of muscle injury. Thus, the cell-source responsible for forming ectopic bone in 
muscle is a subpopulation of muscle-resident PDGFR $\alpha+$ progenitors [13]. Overall, these studies demonstrate that FAPs are a significant cellular source of chondrogenic cells and osteogenic cells in severely damaged muscles.

Remarkably, intramuscular calcium deposits serve as a pathohistological feature of DMD [215]. Notably, the degree of osteogenic commitment of FAPs appears to match the model of muscle damage and degeneration/ regeneration used. Using the severe D2- $m d x$ (DBA/2J$\mathrm{mdx}$ ) dystrophic mice, which better recapitulates the human characteristics of DMD myopathology, Mázala et al. demonstrated that PDGFR $\alpha+$ FAPs accumulate within calcified deposits in degenerative muscles [117]. Also, the in vitro osteogenic differentiation of these cells positively correlates with the degree and extension of muscle degeneration and TGF- $\beta$ levels, which supports previous studies showing that FAPs vastly expand and accumulate accordingly with the extension of damage, TGF- $\beta$ levels, and fibrosis [11, 12, 15, 27, 53, 54, 59, 103, 117]. In summary, FAP activity and responses are highly contextual, which suggests that signals emanating from the local niche determine their phenotypic multi-lineage-fate. Why are different muscle groups affected to a different extent in muscular dystrophy or neuromuscular disorders? Although several hypotheses might explain this, including muscle fiber type, muscle fiber innervation, muscle of origin, calcium homeostasis, and muscle activity, we still lack information of the role that FAPs play in these processes.

\section{Fibro-adipogenic cell diversity: Single-cell omics unveil stromal populations in muscles}

The recent revolution in single-cell omics technologies, including single-cell RNA sequencing (scRNAseq), single-cell epigenomics (e.i. scATACseq), and single-cell mass cytometry (e.i., CyTOF) has helped to uncover the mysteries of muscle cellular composition and heterogeneity as well as to faithfully recreate a more precise cellular atlas of murine and human adult skeletal muscle in homeostasis, regeneration, and repair $[48,58,62,106-$ 109, 111, 216] (Fig. 3). Muscle single-cell analyses faithfully recapitulate key cellular events involved in skeletal muscle regeneration and repair, derived from studies over many years. Such tools and information led us to realize that a complex array of non-myogenic cells (tissue-resident and non-tissue-resident) engage in active cross-talk between each other and with MuSCs to restore tissue function following damage. Single-cell studies evaluate molecular signatures and expression levels of genes or cell surface protein abundance in large numbers of individual cells. They aim to describe at an unprecedented resolution the total interstitial populations of cells in a resting state and to understand their flux in response to injury and disease. Owing to the ability of single-cell omics technologies to refine our understanding of cell heterogeneity by using a plethora of genes and proteins to identify a particular cluster or subpopulation of cells, they are significantly more accurate compared with the use of a single marker to identify cell types.

The classical view of cellular muscle composition is that most of the non-myogenic cells play a positive role and generate a pro-regenerative transitional niche, which, among other functions, support MuSC-driven myogenesis following acute damage [217]. These populations of non-myogenic cells include endothelial cells (CD31+) [218, 219], FAPs (PDGFR $\alpha+)$ [1, 2], connective tissue fibroblasts TCF7L2+ (significantly overlapping with FAPs) [6, 24, 27, 28], pericytes (NG2+, RGS5+) [48], mesoangioblasts [220, 221], tenocytes (TNMD+, SCX+), glial cells (PIP1+, KCNA1+) $[48,58]$, and a complex array of immune cells [222-224].

With single-cell omics technologies, the transcriptional identity in homeostasis and lineage trajectories of muscle-resident FAPs during the regenerative response and in disease states have started to be discovered. Malecova and colleagues were the first to initially show the existence of cellular heterogeneity in muscle FAPs using single-cell RT-PCR and showed that it increases in regenerating muscles [62] (Table 4). The authors showed that a specific subpopulation of vascular cell adhesion molecule VCAM-1+ FAPs vastly expands and drives muscle fibrosis in acute damaged muscles and adult dystrophic muscles of the mdx mice [62]. Notably, the VCAM-1+ subFAPs are absent in uninjured muscles, suggesting that Vcam1 may be an activation marker. Recently, a population of quiescent $\mathrm{HIC} 1+$ mesenchymal progenitor cells has been described. This population contains precursor cells for several mesenchymal lineages including muscle FAPs (Pdgfra+, Ly6a+), tenocytes $($ Tnmd +$)$, pericytes $(R g s 5+)$, and a new subset of cells called myotenocytes (Col22a1+) [48]. However, further functional analyses will be required to confirm if the myotenocyte cells present at the regenerated myotendinous junction represent an independent subpopulation of $\mathrm{HIC} 1+$ progenitors with a specific function or a differentiated cell state of tenocyte progenitors in the myotendinous niche. Even though HIC1 is a broad stromal progenitor marker, FAP gene signatures segregate from other interstitial populations of mesenchymal cells like pericytes and tenocytes [48]. Remarkably, the gene signature of muscle PDGFR $\alpha+$ FAPs is heterogeneous and progresses over time after acute muscle injury, which reveals their dynamic role in regeneration $[48,108]$. Therefore, FAPs acquire a unique plastic transcriptome that changes as the inflammation progresses and damage resolves through regeneration. Concerning mouse muscles, two major FAP populations have been described 


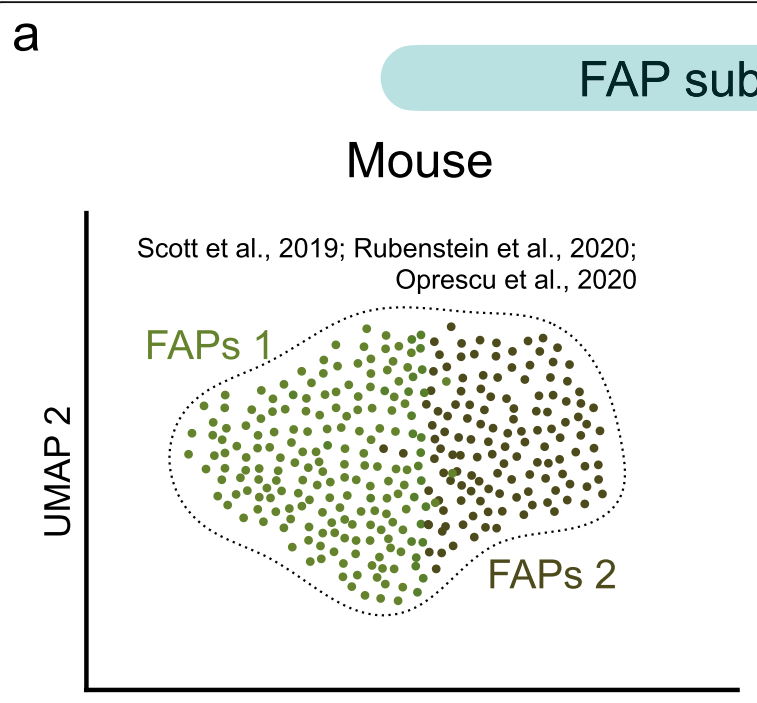

UMAP 1

\section{Human}

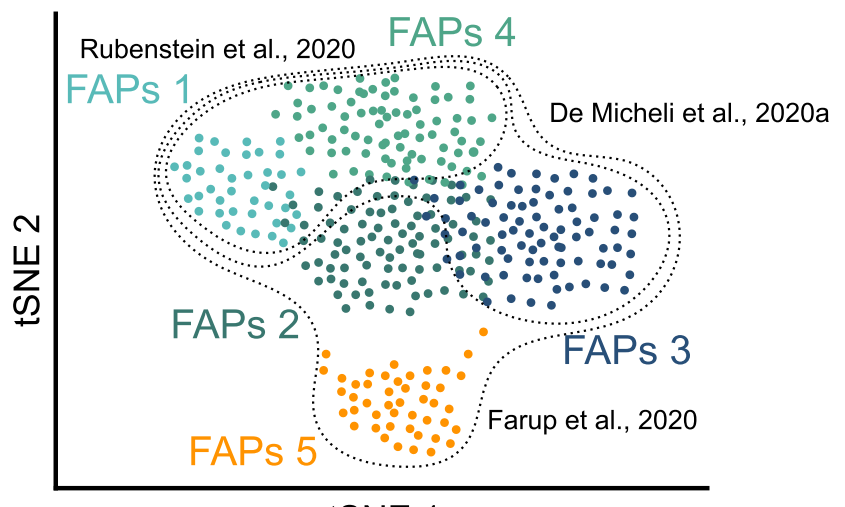

tSNE 1

b Tissue injury

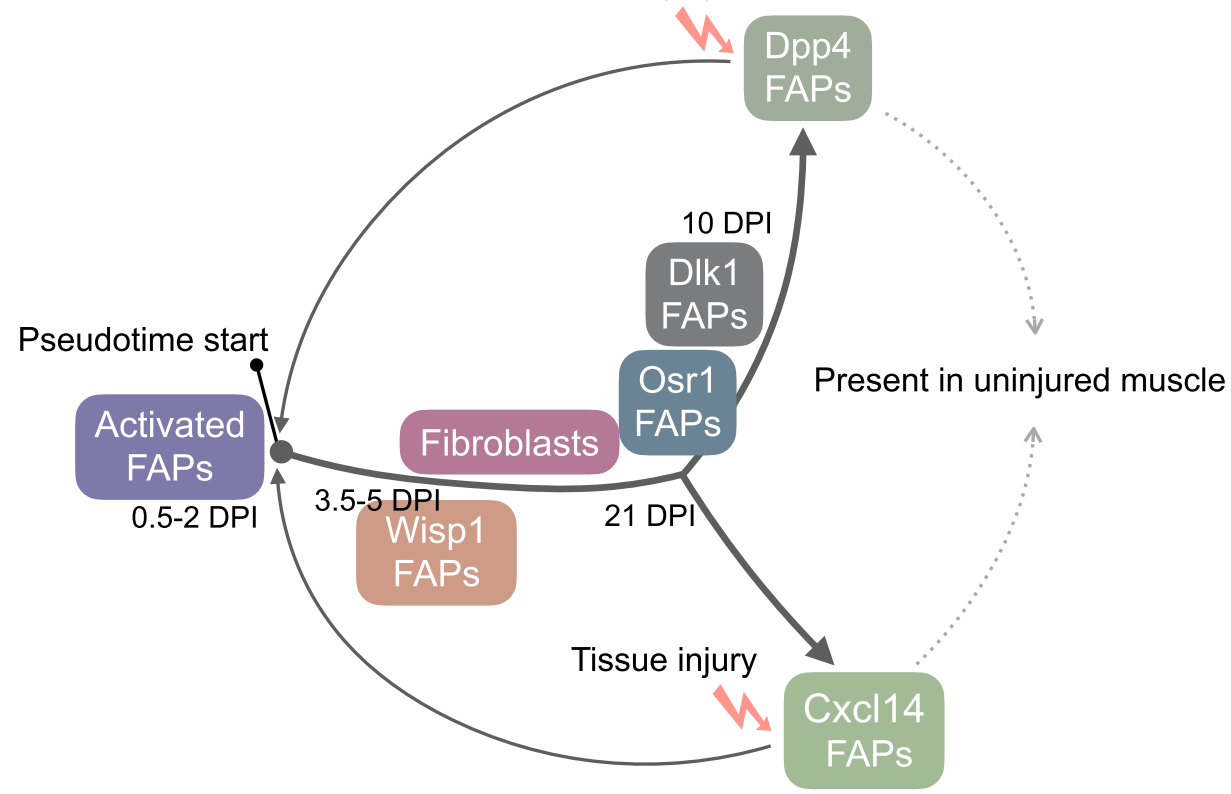

Fig. 3 a Single-cell RNA sequencing analyses to map muscle-resident FAP mononuclear landscape in murine (left graph) and human (right graph) skeletal muscle tissue. Three different studies, utilizing mice, agree with the existence of at least two principal muscle FAP subpopulations (here shown as FAPs 1 and FAPs 2; see text for details). On the other hand, FAP clustering and FAP subpopulations greatly vary in human muscles. Two different bioinformatic techniques for the presentation of large scRNA-seq datasets and their dimensionality reduction are shown: uniform manifold approximation and projection (UMAP) algorithm and t-Distributed Stochastic Neighbor Embedding (t-SNE). Colored dots represent individual FAP cells. Dotted lines illustrate the different studies discussed in this review. $\mathbf{b}$ FAP cell trajectories are based on the gene signatures of single cells following damage $[48,108]$. The transcriptomes of FAPs indicate high cellular heterogeneity within the FAP populations in response to injury. In mouse muscles, two major FAP subpopulations (Dpp4 FAPs and Cxcl14 FAPs) are present in homeostatic conditions (for detailed markers, see Table 4). Analysis of the pseudotime trajectory of different FAP subpopulations suggests that FAP cells follow a continuum and diverge into two major subclusters upon damage 
Table 4 scRNA-seq gene signatures used for FAP identification and clustering in muscle homeostasis

\begin{tabular}{|c|c|c|c|}
\hline Genes/markers & FAP subpopulations & Species & Reference \\
\hline \multirow[t]{2}{*}{ Sca1, Cd34, Pdgfra } & SubFAPs: Tie2 $2^{\text {low }}$ (Tek), Vcam1 low & \multirow[t]{2}{*}{ Mouse } & \multirow[t]{2}{*}[62]{} \\
\hline & SubFAPs: Tie2 $2^{\text {high }}$ (Tek), Vcam $1^{\text {high }}$ & & \\
\hline Ly6a (Sca1), Ly6e, Pdgfra, Dcn & Not determined & Mouse & {$[58]$} \\
\hline \multirow[t]{2}{*}{ Pdgfra, Ly6a (Sca1), Hicl } & FAP1: Cxcl14, Col4, Col6, Col15, Lum, Sparcl1, Podn, Smoc2, Mgp, and Bgn & \multirow[t]{2}{*}{ Mouse } & \multirow[t]{2}{*}{ [48] } \\
\hline & FAP2: Dpp4, Sfrp4, Igfbp5, Sema3c, Tgfrb2, and Wnt2 & & \\
\hline Pdgfra, Ly6a (Sca1), Den, Cd34 & Not determined & Mouse & [216] \\
\hline Pdgfra, Col3a1, Den, and Gsn & Not determined & Mouse & [107] \\
\hline \multirow[t]{2}{*}{ Pdgfra, Ly6a (Sca1), Cd34 } & FAP1: Cxcl14, Enpp2 (Autotaxin), Crispld2, Hsd11b1, Smoc2, Ccl11, Gsn, and Den & \multirow[t]{2}{*}{ Mouse } & \multirow[t]{2}{*}{ [108] } \\
\hline & FAP2: Dpp4, Pi16, Wnt2, Igfbp5, lgfbp6, Fbn1, and Ugdh & & \\
\hline \multirow{2}{*}{$\begin{array}{l}\text { PDGFRA, CD34, COLLAGEN 1, } \\
\text { COLLAGEN 3, and COLLAGEN } 6\end{array}$} & LUMICAN (LUM) FAP: LUM, DCN, CXCL14, COLLAGEN 4, and COLLAGEN 15, SMOC2, and GSN & \multirow{2}{*}{$\begin{array}{l}\text { Mouse } \\
\text { and } \\
\text { human }\end{array}$} & \multirow[t]{2}{*}{ [109] } \\
\hline & FIBRILLIN 1 (FBN1) FAP: FNB1, MFAP5, LOXL1, PRG4, ELN, IGFBP5, and FSTL1 & & \\
\hline \multirow[t]{3}{*}{ PDGFRA } & FAP1 (fibroblasts 1): COL1A1, SFRP4, SERPINE1, and CCL2 & \multirow[t]{3}{*}{ Human } & \multirow[t]{3}{*}{ [106] } \\
\hline & FAP2 (Fibroblast 2): FBN1, MFAP5, and CD55 & & \\
\hline & FAP3 (Fibroblast 3): SMOC2, ADH1B, and $A B C 18$ & & \\
\hline \multirow{5}{*}{$\begin{array}{l}\text { PDGFRA, CD34, COLIA1, COL6A3, } \\
\text { TCF7L2 }\end{array}$} & FAP1: PCOLCE2, MFAP5, IGFBP6, ENNP1, CD55, and AXL & \multirow[t]{5}{*}{ Human } & \multirow[t]{5}{*}[16]{$^{\mathrm{a}}$} \\
\hline & FAP2: LUM, MYOC, CCL2, ADH1B, SFRP2, CXCL14, and MGP & & \\
\hline & FAP3: TNXB, C3, COL15A1, SMOC2, ABCA8, COL6A1, and HMCN2 & & \\
\hline & FAP4: IGF1, CRLF1, SCN7A, ITIH5, PTGDS and NOV & & \\
\hline & FAP5: SEMA3C, PRG4, DEFB1, CCDC80, LINC01133, and IGFBP5 & & \\
\hline
\end{tabular}

${ }^{\mathrm{a}}$ By re-clustering the FAP population, the authors described the existence of 7 different FAP subpopulations in human muscles [16]

(FAP1 and FAP2) in undamaged muscles (Fig. 3a). FAP1 associates with the ECM gene signatures, such as collagens Col4, Col6 and Col15, Lum, Sparcl1, Podn, Smoc2, $M g p, C x c l 14$, and Bgn. On the other hand, the FAP2 subpopulation expresses genes involved in cell signaling and migration, including Sfrp4, Igfbp5, Sema3c, Dpp4, Tgfrb2, and Wnt2 [48] (Table 4). In contrast, another study described no segregation of the FAP population, primarily based on the expression of a few FAP markers [216]. These subtle differences might be explained by a number of technical factors such as muscle groups used for scRNAseq, tissue digestion and cell-type enrichment methods, single-cell RNA sequencing platform-although most of them used Chromium 10× Genomics, the number of cells captured and recovered after sequencing, and downstream data processing (e.g., version of Seurat $\mathrm{R}$ package used) and interpretation.

Oprescu et al. [108] reported that murine CXCL14+ FAPs (also expressing Smoc2, Ccl11, Gsn, and Dcn) and DPP4+ (expressing Pi16, Igfbp5, Igfbp6, Fbn1, and Ugdh) FAPs represent two different FAP subtypes present in non-injured murine tibialis anterior muscle, suggesting that FAPs could represent two distinct subpopulations of interstitial cells in resting conditions, as it was previously shown by us [48] (Table 4). However, in response to injury, the two populations follow a linear trajectory into a single population of activated FAPs (highly expressing chemokine genes like $\mathrm{Cxcl5}, \mathrm{Cxcl3}, \mathrm{Ccl} 7$, and $\mathrm{Ccl} 2$ ) at 0.5 and 2-day post-injury (DPI), then progressing into WISP1+ FAPs at 3.5 and 5 DPI (highly expressing Postn, Csrp2, Sfrp2, Ptn, Cilp, and Cthrc1), followed by DLK1+ FAPs at 10 DPI (expressing Itm2a, B830012L14Rik, Meg3, Airn, Peg3, Zim1, H19, and Igf2), and finally two FAP subpopulations at day $21 \mathrm{DPI}$, OSR1+ (expressing Gsn, Ccl1, Bmp4, Bmp5, and Wnt5a) and fibroblast FAPs (expressing Col3a1, Col1a1, Col1a2, Col6a3, and Meg3) [108] (Table 4 and Fig. 3b). Notably, the authors showed that a proportion of the OSR1+ FAPs at 21 DPI diverge into the two populations observed in undamaged muscle: DPP4+ FAPs and CXCL14+ FAPs (Fig. 3b). Therefore, the gene expression of single-cell FAPs is highly diverse, representing a continuum state during skeletal muscle regeneration (Fig. 3b). Owing to the high degree of FAPs diversity, we speculate that FAP subpopulations have adapted to play supportive and distinct roles during regeneration. These data also suggest that the transcriptional diversity of PDGFR $\alpha+$ FAPs at the single-cell level might reflect their differential developmental potential.

In addition to these studies, Rubenstein et al. [109] described two human FAP subpopulations as LUMICAN (LUM)+ FAP and FIBRILLIN 1 (FBN1)+ FAP subtypes (Table 4 and Fig. 3a). Interestingly, both FAP subpopulations showed specific differences in the expression of 
Collagen types. The authors also validated the existence of these two distinct FAP subtypes by using scRNAseq of mouse quadriceps and diaphragm muscles [109]. ECM gene expression was also consistent among mouse and human muscles, with COLLAGEN 1, COLLAGEN 3, and COLLAGEN 6 broadly expressed across FAP subpopulations. In contrast, LUM+ FAPs express COLLAGEN 4, and COLLAGEN 15 predominantly compared with FBN1+ FAPs (Table 4). Interestingly, the authors reported differences in the gene expression of the precursor gene of TIE2 protein among the two species, which was expressed only in the FBN1+ FAP subtype found in mouse muscle but none of the FAP subtypes found in human muscles. The meaning of these subtle differences in gene expression across mouse and human muscle FAP subtypes should be address in future research.

De Micheli and collegues collected and integrated 22,000 single-cell transcriptomes generating for the first time a consensus cell atlas of human skeletal muscles [106] (Table 4 and Fig. 3a). The authors described three subpopulations of fibroblasts (likely FAPs) in which COLLAGEN 1, SFRP4, SERPINE1 and CCL2 are highly expressed by fibroblast 1; FBN1+, MFAP5, and CD55 are expressed by fibroblast 2, whereas fibroblast 3 highly expresses SMOC2 [106, 107] (Table 4).

Recently, Farup and colleagues described 5 subpopulations of human muscle FAPs (Table 4 and Fig. 3a). However, by sub-setting the FAP population and reclustering, the number of clusters increased to 7 . The authors reported that the expression of THY1/CD 90 is enriched in cluster 4, whereas PDGFRA gene expression is broadly distributed among the FAP subpopulations (Table 4). Remarkably, the CD90+ subpopulation of FAPs is associated with increased fibro-fatty infiltration and seems to drive the muscle degeneration found in obese and type- 2 diabetes patients [16]. Although the composition of each cellular interstitial compartment changes dramatically after injury and in disease settings in mice, there is no information about how the FAP population behaves following injury or how degenerative diseases alter its activities in humans. Nonetheless, we and others have detected a diverse range of mesenchymal stromal cells including quiescent subsets, which rapidly expand following injury and secrete cytokines modulating inflammation, trophic factors, and regenerative cues to promote skeletal muscle maintenance, MuSC renewal, and regeneration.

In conclusion, further studies should focus on understanding the mechanisms by which FAP cell heterogeneity arises. We aim to understand the lineage restriction of FAPs by gene regulatory networks and epigenetic factors that, in combination with the extrinsic effects of the spatial context could regulate their fate and plasticity within muscles. Although there has been encouraging progress in understanding FAP phenotypic variability and activities, future research should look to translating this knowledge into efficient medical applications.

\section{Future perspectives}

Skeletal muscle requires a complex orchestra of specialized populations of cells to perform its crucial functions. The origin, behavioral activities, lineage potency, and expression of markers associated with stem or progenitor cell states define these specialized cell types. Here, we have focused on the unappreciated role of PDGFR $\alpha+$ FAPs in muscle biology, health, structure, and regeneration. Apart from the accepted structural part that the connective tissue provides for proper muscle development, the complex cues and matrix that stromal cells produce are essential to sustain myogenesis and support proper muscle morphogenesis. FAPs are implicated in muscle scarring, disease, and pathology. Although substantial progress has been made in understanding FAP behavior, they remain poorly characterized, and the relationships with other stromal cells are not well understood. PDGFR $\alpha+$ FAPs and their descendant lineages, including activated-fibroblasts/myofibroblasts, adipocytes, chondrogenic and osteogenic cells, modulate muscle regeneration and repair. These plastic cells play broad roles as sentinels, stress sensors, immune regulators, cellular hubs, and paracrine factories, which are still under active research in multiple pathological settings.

As discussed above, lineage tracing technologies combined with single-cell sequencing strategies should bypass the significant limitations that historically prevented us from deconvolving the complexity of stromal cell populations. The diverse fibroblast nomenclature has periodically led to confusing claims in muscle biology and ensuing turmoil in the literature. Thus, resolving the regenerative vs. reparative dichotomy of muscle-resident mesenchymal progenitors, and distinguishing true lineage heterogeneity from the diverse functional states that these cells can dynamically and reversibly acquire remains a high-priority issue for the field. Despite these various uncertainties, in this review, we establish a baseline for the contribution of fibroadipogenic progenitors to muscle development, homeostasis, regeneration, and repair.

\section{Conclusions}

In this review, we document new insights about the various properties of muscle-resident PDGFR $\alpha+$ FAPs and discuss the current state of knowledge on their origins and lineage capabilities. Here we propose to define a cell as FAP if they present the following characteristics: 1 . Express PDGFR $\alpha$ at the gene and protein level. 2. It is 
located in the tissue's interstitium and behaves as a perivascular cell but not residing in the blood vessel cavity. 3. It can form colonies in vitro. 4. Can differentiate into activated fibroblasts, adipocytes, chondrocytes, and osteocytes in vitro and in vivo.

We illustrated their importance in maintaining proper muscle function and critical role during the onset and establishment of scarring in pathology and disease. Growing evidence shows that PDGFR $\alpha+$ cells are heterogeneous and act as signaling hubs by providing regenerative cues and integrating these signals in the muscle niche. Thus, FAPs influence other populations of cells within skeletal muscle and vice versa. Ultimately, by understanding and manipulating the complexity and variability of the stromal compartment, specifically the FAP lineage, we aim to develop novel therapeutics to treat several scar-forming pathologies. It remains plausible to foresee a future where clinical leaps could be made based on these cells and where severe muscle injury could be treated without prolonged myodegeneration and muscle malfunctioning.

\begin{abstract}
Abbreviations
aSMA: Alpha smooth muscle actin; BMP: Bone morphogenetic protein; CFU: Colony-forming unit; CDHs: Congenital diaphragmatic hernias; CT: Connective tissue; DMD: Duchenne muscular dystrophy; DTA: Diphteria toxin A; DTR: Diphteria toxin receptor; ECM: Extracellular matrix; FAPa: Fibroblast activation protein alpha; FAPs: Fibro-adipogenic progenitors; FOP: Fibrodysplasia ossificans progressiva; GSK: Glycogen Synthase Kinase-3; HO: Heterotopic ossification; IL: Interleukin; IMAT: Intermuscular adipose tissue; LGMD: Limb-girdle muscular dystrophy; Lox: Lysyl oxidase; MSCs: Mesenchymal stem cells; MCT: Muscle connective tissue; MuSCs: Muscle stem cells; NCCs: Neural crest cells; PDGFRa: Platelet-derived growth factor receptor alpha; PDGFRß: Platelet-derived growth factor receptor beta; PDGF: Platelet-derived growth factor; PPFs: Pleuroperitoneal folds; OSR: Odd-skipped-related; Shh: Sonic Hedgehog signaling; Sca-1: Stem cell antigen-1; Tbx: T-box transcription factor; TIMP3: Tissue inhibitor of metalloproteinases 3; TCF21: Transcription factor 21; TGF- $\beta$ : Transforming growth factor beta; UPS: Ubiquitin-proteasome system
\end{abstract}

\section{Acknowledgements}

The authors acknowledge Yen Tran and Ralph Patrick for helpful suggestions to the single-cell omics chapter, and Lucas Rempel for his inputs improving the review. Figures were created using Illustrator (Adobe Inc.) and Keynote (Apple Inc.) for macOS.

\section{Authors' contributions}

O.C. and M.T. drafted the review and figures. F.M.V.R. revised and reviewed the manuscript. All authors read and approved the final manuscript.

\section{Funding}

This work was supported by Comisión Nacional de Ciencia y Tecnología CONICYT Beca Doctorado Nacional 2014 folio 21140378 "National Doctorate Fellowship", by Centro Basal de Excelencia en Envejecimiento y Regeneración (CONICYT-AFB 170005), and by the Victor Chang Cardiac Research Institute to O.C.; by Fondation pour la Recherche Médicale (FRM, 40248), by the European Molecular Biology Organization (EMBO, ALTF 1152016), by the Association contre les myopathies (AFM, 22576), and by Michael Smith Foundation for Health Research (MSFHR, 18351) to M.T.; and by the Canadian Institutes of Health Research (CIHR-FDN-159908) to F.M.V.R. The funding agencies had no role in the design of the study, data collection and analysis, the decision to publish, or preparation of the manuscript.

\section{Availability of data and materials}

All data generated or analyzed during this study are included in this published article.

\section{Declarations}

Ethics approval and consent to participate

Not applicable.

\section{Consent for publication}

Not applicable.

\section{Competing interests}

The authors declare that they have no competing interests.

\section{Author details}

'Developmental and Stem Cell Biology Division, Victor Chang Cardiac Research Institute, Darlinghurst, NSW 2010, Australia. ${ }^{2}$ St. Vincent's Clinical School, Faculty of Medicine, UNSW Sydney, Kensington 2052, Australia. ${ }^{3}$ Departamento de Biología Celular y Molecular and Center for Aging and Regeneration (CARE-ChileUC), Facultad de Ciencias Biológicas, Pontificia Universidad Católica de Chile, 8331150 Santiago, Chile. ${ }^{4}$ Biomedical Research Centre, Department of Medical Genetics and School of Biomedical Engineering, University of British Columbia, Vancouver, BC V6T 1Z3, Canada.

Received: 22 January 2021 Accepted: 22 March 2021

Published online: 01 July 2021

\section{References}

1. Joe AWB, et al. Muscle injury activates resident fibro/adipogenic progenitors that facilitate myogenesis. Nat Cell Biol. 2010;12(2):153-63 https://doi.org/1 $0.1038 /$ ncb2015

2. Uezumi A, et al. Mesenchymal progenitors distinct from satellite cells contribute to ectopic fat cell formation in skeletal muscle. Nat Cell Biol. 2010;12(2):143-52 https://doi.org/10.1038/ncb2014

3. Fiore $D$, et al. Pharmacological blockage of fibro/adipogenic progenitor expansion and suppression of regenerative fibrogenesis is associated with impaired skeletal muscle regeneration. Stem Cell Res. 2016;17(1):161-9 https://doi.org/10.1016/j.scr.2016.06.007.

4. Heredia JE, et al. Type 2 innate signals stimulate fibro/adipogenic progenitors to facilitate muscle regeneration. Cell. 2013;153(2):376-88 https://doi.org/10.1016/j.cell.2013.02.053.

5. Lukjanenko L, et al. Aging disrupts muscle stem cell function by impairing matricellular WISP1 Secretion from fibro-adipogenic progenitors. Cell Stem Cell United States. 2019;24(3):433-446.e7 https://doi.org/10.1016/j.stem.201 8.12.014.

6. Murphy MM, et al. Satellite cells, connective tissue fibroblasts and their interactions are crucial for muscle regeneration. Development. 2011;138(17): 3625-37 https://doi.org/10.1242/dev.064162.

7. Wosczyna MN, et al. Mesenchymal Stromal Cells Are Required for Regeneration and Homeostatic Maintenance of Skeletal Muscle. Cell Rep. 2019;27(7):2029-2035.e5 https://doi.org/10.1016/j.celrep.2019.04.074.

8. Roberts EW, et al. Depletion of stromal cells expressing fibroblast activation protein-a from skeletal muscle and bone marrow results in cachexia and anemia. J Exp Med. 2013;210(6):1137-51 https://doi.org/10.1084/jem.2 0122344.

9. Uezumi A, et al. Mesenchymal Bmp3b expression maintains skeletal muscle integrity and decreases in age-related sarcopenia. J Clin Investig. 2021; 131(1) https://doi.org/10.1172/JCl139617.

10. Santini MP, et al. Tissue-Resident PDGFRa+ Progenitor Cells Contribute to Fibrosis versus Healing in a Context- and Spatiotemporally Dependent Manner. Cell Rep. 2020;30(2):555-570.e7 https://doi.org/10.1016/j.celrep.201 9.12.045.

11. Contreras O, Cruz-Soca M, Theret M, Soliman H, Tung LW, Groppa E, et al. Cross-talk between TGF- $\beta$ and PDGFRa signaling pathways regulates the fate of stromal fibro-adipogenic progenitors. J Cell Sci. 2019;132:jcs232157 https://doi.org/10.1242/jcs.232157.

12. Contreras O, Rossi FM, Brandan E. Adherent muscle connective tissue fibroblasts are phenotypically and biochemically equivalent to stromal fibro/ adipogenic progenitors. Matrix Biol Plus. 2019;2:100006 https://doi.org/10.1 016/j.mbplus.2019.04.003. 
13. Eisner $C$, et al. Murine Tissue-Resident PDGFRa+ Fibro-Adipogenic Progenitors Spontaneously Acquire Osteogenic Phenotype in an Altered Inflammatory Environment. J Bone Miner Res. 2020;35(8):1525-34 https:// doi.org/10.1002/jbmr.4020.

14. Kopinke D, Roberson EC, Reiter JF. Ciliary Hedgehog Signaling Restricts Injury-Induced Adipogenesis. Cell. 2017;170(2):340-351.e12 https://doi.org/1 0.1016/j.cell.2017.06.035.

15. Uezumi A, et al. Fibrosis and adipogenesis originate from a common mesenchymal progenitor in skeletal muscle. J Cell Sci. 2011;124(21):3654-64 https://doi.org/10.1242/jcs.086629.

16. Farup J, et al. Human skeletal muscle CD90+ fibro-adipogenic progenitors are associated with muscle degeneration in type 2 diabetic patients. bioRxiv. 2020:2020.08.25.243907 https://doi.org/10.1101/2020.08.25.243907.

17. Chapman MA, et al. Three distinct cell populations express extracellular matrix proteins and increase in number during skeletal muscle fibrosis. Am J Physiol Cell Physiol. 2016a;312(2):C131-43 https://doi.org/10.1152/ajpcell. 00226.2016.

18. Chapman MA, Meza R, Lieber RL. Skeletal muscle fibroblasts in health and disease. Differentiation. 2016b:108-15 https://doi.org/10.1016/j.diff.2016.05. 007.

19. Gillies AR, Lieber RL. Structure and function of the skeletal muscle extracellular matrix. Muscle Nerve. 2011:318-31 https://doi.org/10.1002/ mus.22094.

20. Helmbacher F, Stricker $\mathrm{S}$. Tissue cross talks governing limb muscle development and regeneration. Semin Cell Dev Biol. 2020:14-30 https://doi. org/10.1016/j.semcdb.2020.05.005.

21. Nassari S, Duprez D, Fournier-Thibault C. Non-myogenic contribution to muscle development and homeostasis: The role of connective tissues. Front Cell Dev Biol. 2017; https://doi.org/10.3389/fcell.2017.00022.

22. Sefton EM, Kardon G. Connecting muscle development, birth defects, and evolution: An essential role for muscle connective tissue. Curr Top Dev Biol. 2019:137-76 https://doi.org/10.1016/bs.ctdb.2018.12.004

23. Kardon G, Harfe BD, Tabin CJ. A Tcf4-positive mesodermal population provides a prepattern for vertebrate limb muscle patterning. Dev Cell. 2003; 5(6):937-44 https://doi.org/10.1016/S1534-5807(03)00360-5.

24. Mathew SJ, et al. Connective tissue fibroblasts and Tcf4 regulate myogenesis. Development. 2011;138(2):371-84 https://doi.org/10.1242/dev 057463

25. Kardon G, Campbell JK, Tabin CJ. Local extrinsic signals determine muscle and endothelial cell fate and patterning in the vertebrate limb. Dev Cell. 2002;3(4):533-45 https://doi.org/10.1016/S1534-5807(02)00291-5.

26. Vallecillo-García P, et al. Odd skipped-related 1 identifies a population of embryonic fibro-adipogenic progenitors regulating myogenesis during limb development. Nat Commun. 2017;8(1) https://doi.org/10.1038/s41467-01701120-3.

27. Contreras O, Rebolledo DL, Oyarzún JE, Olguín HC, Brandan E. Connective tissue cells expressing fibro/adipogenic progenitor markers increase under chronic damage: relevance in fibroblast-myofibroblast differentiation and skeletal muscle fibrosis. Cell Tissue Res. 2016:364:647-60 https://doi.org/10.1 007/s00441-015-2343-0.

28. Contreras O, Soliman $H$, Theret M, Rossi FMV, Brandan E. TGF- $\beta$-driven downregulation of the transcription factor TCF7L2 affects Wnt/ $\beta$-catenin signaling in PDGFRa+ fibroblasts. J Cell Sci. 2020;133 https://doi.org/1 $0.1242 / j c s .242297$.

29. Nowicki JL, Takimoto R, Burke AC. The lateral somitic frontier: Dorso-ventra aspects of anterio-posterior regionalization in avian embryos. Mech Dev. 2003;120(2):227-40 https://doi.org/10.1016/S0925-4773(02)00415-X.

30. Pearse RV, et al. A cellular lineage analysis of the chick limb bud. Dev Biol. 2007;310(2):388-400 https://doi.org/10.1016/j.ydbio.2007.08.002.

31. Noden DM. The embryonic origins of avian cephalic and cervical muscles and associated connective tissues. Am J Anat. 1983a;168(3):257-76 https:// doi.org/10.1002/aja.1001680302.

32. Noden DM. The role of the neural crest in patterning of avian cranial skeletal, connective, and muscle tissues. Dev Biol. 1983b;96(1):144-65 https://doi.org/10.1016/0012-1606(83)90318-4.

33. Olsson L, et al. Cranial neural crest cells contribute to connective tissue in cranial muscles in the anuran amphibian, Bombina orientalis. Dev Biol. 2001; 237(2):354-67 https://doi.org/10.1006/dbio.2001.0377.

34. Theis $\mathrm{S}$, et al. The occipital lateral plate mesoderm is a novel source for vertebrate neck musculature. Development. 2010;137(17):2961-71 https:// doi.org/10.1242/dev.049726.
35. Merrell AJ, et al. Muscle connective tissue controls development of the diaphragm and is a source of congenital diaphragmatic hernias. Nat Genet. 2015;47(5):496-504 https://doi.org/10.1038/ng.3250.

36. Hasson $\mathrm{P}$, et al. Tbx4 and Tbx5 Acting in Connective Tissue Are Required for Limb Muscle and Tendon Patterning. Dev Cell. 2010;18(1):148-56 https:// doi.org/10.1016/j.devcel.2009.11.013.

37. Li QY, et al. Holt-Oram syndrome is caused by mutations in TBX5, a member of the Brachyury (T) gene family. Nat Genet. 1997:21-9 https://doi. org/10.1038/ng0197-21.

38. Kutchuk $L$, et al. Muscle composition is regulated by a lox-TGF $\beta$ feedback loop. Development (Cambridge). 2015; https://doi.org/10.1242/dev.113449.

39. Besse L, et al. Individual Limb Muscle Bundles Are Formed through Progressive Steps Orchestrated by Adjacent Connective Tissue Cells during Primary Myogenesis. Cell Rep. 2020;30(10):3552-3565.e6 https://doi.org/10.1 016/j.celrep.2020.02.037.

40. Colasanto MP, et al. Development of a subset of forelimb muscles and their attachment sites requires the ulnar-mammary syndrome gene Tbx3. DMM Dis Models Mech. 2016;9(11):1257-69 https://doi.org/10.1242/dmm.025874.

41. Duboule D, Dolle P. The structural and functional organization of the murine HOX gene family resembles that of Drosophila homeotic genes. EMBO J. 1989;8(5):1497-505 https://doi.org/10.1002/j.1460-2075.1989.tb03 534.x.

42. Boulet AM, Capecchi MR. Duplication of the Hoxd11 gene causes alterations in the axial and appendicular skeleton of the mouse. Dev Biol. 2002;249(1): 96-107 https://doi.org/10.1006/dbio.2002.0755.

43. Boulet AM, Capecchi MR. Multiple roles of Hoxa11 and Hoxd11 in the formation of the mammalian forelimb zeugopod. Development. 2004 131(2):299-309 https://doi.org/10.1242/dev.00936.

44. Davis AP, et al. Absence of radius and ulna in mice lacking hoxa-11 andhoxd-11. Nature. 1995:375(6534):791-5 https://doi.org/10.1038/375791a0.

45. limura T, Pourquié $O$. Hox genes in time and space during vertebrate body formation. Develop Growth Differ. 2007:265-75 https://doi.org/10.1111/j.144 0-169X.2007.00928.x

46. Swinehart IT, et al. Hox11 genes are required for regional patterning and integration of muscle, tendon and bone. Development (Cambridge). 2013; 140(22):4574-82 https://doi.org/10.1242/dev.096693.

47. Alfaro LAS, et al. CD34 promotes satellite cell motility and entry into proliferation to facilitate efficient skeletal muscle regeneration. Stem Cells. 2011;29(12):2030-41 https://doi.org/10.1002/stem.759.

48. Scott RW, et al. Hic1 Defines Quiescent Mesenchymal Progenitor Subpopulations with Distinct Functions and Fates in Skeletal Muscle Regeneration. Cell Stem Cell. 2019;25(6):797-813.e9 https://doi.org/10.1016/j. stem.2019.11.004.

49. Dellavalle A, et al. Pericytes resident in postnatal skeletal muscle differentiate into muscle fibres and generate satellite cells. Nat Commun. 2011;2(1) https://doi.org/10.1038/ncomms1508.

50. Agley CC, et al. Human skeletal muscle fibroblasts, but not myogenic cells, readily undergo adipogenic differentiation. J Cell Sci. 2013;126(24):5610-25 https://doi.org/10.1242/jcs.132563.

51. Arrighi $\mathrm{N}$, et al. Characterization of adipocytes derived from fibro/ adipogenic progenitors resident in human skeletal muscle. Cell Death Dis. 2015;6(4) https://doi.org/10.1038/cddis.2015.79

52. Mackey $\mathrm{AL}$, et al. Human skeletal muscle fibroblasts stimulate in vitro myogenesis and in vivo muscle regeneration. J Physiol. 2017;595(15):511527 https://doi.org/10.1113/JP273997.

53. Uezumi A, et al. Identification and characterization of PDGFR + mesenchymal progenitors in human skeletal muscle. Cell Death Dis. 2014a; 5(4) https://doi.org/10.1038/cddis.2014.161.

54. Uezumi A, Ikemoto-Uezumi M, Tsuchida K. Roles of nonmyogenic mesenchymal progenitors in pathogenesis and regeneration of skeletal muscle. Front Physiol. 2014b; https://doi.org/10.3389/fphys.2014.00068.

55. Stricker $\mathrm{S}$, et al. Comparative expression pattern of Odd-skipped related genes Osr1 and Osr2 in chick embryonic development. Gene Expr Patterns. 2006:6(8):826-34 https://doi.org/10.1016/j.modgep.2006.02.003.

56. Stricker $\mathrm{S}$, et al. Odd-skipped related genes regulate differentiation of embryonic limb mesenchyme and bone marrow mesenchymal stromal cells. Stem Cells Dev. 2012;21(4):623-33 https://doi.org/10.1089/scd.2011. 0154

57. Dulauroy S, et al. Lineage tracing and genetic ablation of ADAM12 + perivascular cells identify a major source of profibrotic cells during acute tissue injury. Nat Med. 2012;18(8):1262-70 https://doi.org/10.1038/nm.2848. 
58. Giordani $L$, et al. High-Dimensional Single-Cell Cartography Reveals Novel Skeletal Muscle-Resident Cell Populations. Mol Cell. 2019;74(3):609-621.e6 https://doi.org/10.1016/j.molcel.2019.02.026.

59. Lemos DR, et al. Nilotinib reduces muscle fibrosis in chronic muscle injury by promoting TNF-mediated apoptosis of fibro/adipogenic progenitors. Nat Med. 2015:21(7):786-94 https://doi.org/10.1038/nm.3869.

60. Lees-Shepard JB, et al. Palovarotene reduces heterotopic ossification in juvenile fop mice but exhibits pronounced skeletal toxicity. eLife. 2018;7 https://doi.org/10.7554/eLife.40814

61. Madaro L, et al. Denervation-activated STAT3-IL-6 signalling in fibroadipogenic progenitors promotes myofibres atrophy and fibrosis. Nat Cell Biol. 2018;20(8):917-27 https://doi.org/10.1038/s41556-018-0151-y.

62. Malecova B, et al. Dynamics of cellular states of fibro-adipogenic progenitors during myogenesis and muscular dystrophy. Nat Commun. 2018;9(1) https://doi.org/10.1038/s41467-018-06068-6.

63. Petrilli $L L$, et al. High-Dimensional Single-Cell Quantitative Profiling of Skeletal Muscle Cell Population Dynamics during Regeneration. Cells. 2020; 9(7) https://doi.org/10.3390/cells9071723.

64. Uezumi A, et al. Cell-Surface Protein Profiling Identifies Distinctive Markers of Progenitor Cells in Human Skeletal Muscle. Stem Cell Rep. 2016;7(2):26378 https://doi.org/10.1016/j.stemcr.2016.07.004

65. Yao $L$, et al. Gli1 defines a subset of fibroadipogenic progenitors that promote skeletal muscle regeneration with less fat accumulation. J Bone Miner Res. 2021; https://doi.org/10.1002/jbmr.4265.

66. Giuliani G, Vumbaca S, Fuoco C, Gargioli C, Giorda E, Massacci G, et al. SCA-1 micro-heterogeneity in the fate decision of dystrophic fibro/ adipogenic progenitors. Cell Death Dis. 2021;12 https://doi.org/10.1038/ s41419-021-03408-1.

67. Stumm J, et al. Odd skipped-related 1 (Osr1) identifies muscle-interstitial fibro-adipogenic progenitors (FAPs) activated by acute injury. Stem Cell Res. 2018;32:8-16 https://doi.org/10.1016/j.scr.2018.08.010.

68. Kramann R, et al. Perivascular Gli1+ progenitors are key contributors to injury-induced organ fibrosis. Cell Stem Cell. 2015;16(1):51-66 https://doi. org/10.1016/j.stem.2014.11.004.

69. Zhao $L$, et al. Retinoic acid signalling in fibro/adipogenic progenitors robustly enhances muscle regeneration. EBioMedicine. 2020;60 https://doi. org/10.1016/j.ebiom.2020.103020.

70. Xi H, Langerman J, Sabri S, Chien P, Young CS, Younesi S, et al. A human skeletal muscle atlas identifies the trajectories of stem and progenitor cells across development and from human pluripotent stem cells. Cell Stem Cell. 2020;27(1):158-76.e10 https://doi.org/10.1016/j.stem.2020.04.017.

71. Goloviznina NA, et al. Prospective isolation of human fibroadipogenic progenitors with CD73. Heliyon. 2020;6(7) https://doi.org/10.1016/j.heliyon.2 020.e04503.

72. Kasai T, et al. Promethazine Hydrochloride Inhibits Ectopic Fat Cell Formation in Skeletal Muscle. Am J Pathol. 2017;187(12):2627-34 https://doi. org/10.1016/j.ajpath.2017.08.008.

73. Soliman $\mathrm{H}$, et al. Pathogenic Potential of Hic1-Expressing Cardiac Stromal Progenitors. Cell Stem Cell. 2020;26(2):205-220.e8 https://doi.org/10.1016/j. stem.2019.12.008.

74. Chong JJH, et al. Adult cardiac-resident MSC-like stem cells with a proepicardial origin. Cell Stem Cell. 2011;9(6):527-40 https://doi.org/10.1016/ j.stem.2011.10.002.

75. Noseda M, et al. PDGFRa demarcates the cardiogenic clonogenic Sca1+ stem/progenitor cell in adult murine myocardium. Nat Commun. 2015;6 https://doi.org/10.1038/ncomms7930.

76. Chen WY, et al. Heterozygous disruption of Hic1 predisposes mice to a gender-dependent spectrum of malignant tumors. Nat Genet. 2003;33(2): 197-202 https://doi.org/10.1038/ng1077.

77. Van Rechem C, et al. Differential Regulation of HIC1 Target Genes by CtBP and NuRD, via an Acetylation/SUMOylation Switch, in Quiescent versus Proliferating Cells. Mol Cell Biol. 2010;30(16):4045-59 https://doi.org/10.1128/ mcb.00582-09.

78. Lepper C, Partridge TA, Fan CM. An absolute requirement for pax7-positive satellite cells in acute injury-induced skeletal muscle regeneration. Development. 2011;138(17):3639-46 https://doi.org/10.1242/dev.067595.

79. Relaix F, Zammit PS. Satellite cells are essential for skeletal muscle regeneration: The cell on the edge returns centre stage. Development (Cambridge). 2012;139(16):2845-56 https://doi.org/10.1242/dev.069088
80. Sambasivan $\mathrm{R}$, et al. Pax7-expressing satellite cells are indispensable for adult skeletal muscle regeneration. Development. 2011;138(17):3647-56 https://doi.org/10.1242/dev.067587.

81. lismaa, S. E. et al. (2018) Comparative regenerative mechanisms across different mammalian tissues, npj Regenerative Medicine. doi: https://doi. org/10.1038/s41536-018-0044-5.

82. Sandoval-Guzmán T, Currie JD. The journey of cells through regeneration. Curr Opin Cell Biol. 2018:36-41 https://doi.org/10.1016/j.ceb.2018.05.008.

83. Wells JM, Watt FM. Diverse mechanisms for endogenous regeneration and repair in mammalian organs. Nature. 2018:322-8 https://doi.org/10.1038/s41 586-018-0073-7.

84. Cordero-Espinoza L, Huch M. The balancing act of the liver: tissue regeneration versus fibrosis. J Clin Investig. 2018:85-96 https://doi.org/10.11 72/JCI93562.

85. Dadgar $\mathrm{S}$, et al. Asynchronous remodeling is a driver of failed regeneration in Duchenne muscular dystrophy. J Cell Biol. 2014;207(1):139-58 https://doi. org/10.1083/jcb.201402079.

86. Pessina $P$, et al. Novel and optimized strategies for inducing fibrosis in vivo: Focus on Duchenne Muscular Dystrophy. Skelet Muscle. 2014;4(1) https:// doi.org/10.1186/2044-5040-4-7.

87. Bendall JR. The elastin content of various muscles of beef animals. J Sci Food Agric. 1967;18(12):553-8 https://doi.org/10.1002/jsfa.2740181201.

88. Dransfield E. Intramuscular composition and texture of beef muscles. J Sci Food Agric. 1977;28(9):833-42 https://doi.org/10.1002/jsfa.2740280910.

89. Vognarová I, Dvorák Z, Böhm R. Collagen and Elastin in Different Cuts of Veal and Beef. J Food Sci. 1968;33(4):339-43 https://doi.org/10.1111/j.1365-2 621.1968.tb03626.x.

90. Light N, Champion AE. Characterization of muscle epimysium, perimysium and endomysium collagens. Biochem J. 1984;219(3):1017-26 https://doi. org/10.1042/bj2191017.

91. Purslow PP. The Structure and Role of Intramuscular Connective Tissue in Muscle Function. Front Physiol. 2020; https://doi.org/10.3389/fphys.2 020.00495 .

92. Borg TK, Caulfield JB. Morphology of connective tissue in skeletal muscle. Tissue Cell. 1980;12(1):197-207 https://doi.org/10.1016/0040-81 66(80)90061-0.

93. Carnwath JW, Shotton DM. Muscular dystrophy in the mdx mouse: Histopathology of the soleus and extensor digitorum longus muscles. J Neurol Sci. 1987;80(1):39-54 https://doi.org/10.1016/0022-510X(87)90219-X.

94. Duance $\mathrm{VC}$, et al. A role for collagen in the pathogenesis of muscular dystrophy? Nature. 1980;284(5755):470-2 https://doi.org/10.1038/284470a0.

95. Gatchalian CL, Schachner M, Sanes JR. Fibroblasts that proliferate near denervated synaptic sites in skeletal muscle synthesize the adhesive molecules tenascin(J1), N-CAM, fibronectin, and a heparan sulfate proteoglycan. J Cell Biol. 1989;108(5):1873-90 https://doi.org/10.1083/jcb.1 08.5.1873.

96. Klingler $W$, et al. The role of fibrosis in Duchenne muscular dystrophy. Acta Myologica. 2012;31(3):184-95.

97. Lieber RL, Ward SR. Cellular mechanisms of tissue fibrosis. 4. structural and functional consequences of skeletal muscle fibrosis. Am J Physiol Cell Physiol. 2013;305(3) https://doi.org/10.1152/ajpcell.00173.2013.

98. Morrison J, et al. T-cell-dependent fibrosis in the $\mathrm{mdx}$ dystrophic mouse. Lab Investig. 2000:80(6):881-91 https://doi.org/10.1038/labinvest.3780092.

99. Serrano $\mathrm{AL}$, et al. Cellular and molecular mechanisms regulating fibrosis in skeletal muscle repair and disease. Curr Top Dev Biol. 2011; https://doi.org/1 0.1016/B978-0-12-385940-2.00007-3.

100. Williams PE, Goldspink G. Connective tissue changes in immobilised muscle J Anat. 1984;138(Pt 2):343-50 Available at: http://www.ncbi.nlm.nih.gov/ pubmed/6715254\%0A, http://www.pubmedcentral.nih.gov/articlerender. fcgi?artid=PMC1164074.

101. Jackson WM, et al. Mesenchymal progenitor cells derived from traumatized human muscle. J Tissue Eng Regen Med. 2009;3(2):129-38 https://doi.org/1 $0.1002 /$ term.149.

102. Dammone $\mathrm{G}$, et al. PPARy controls ectopic adipogenesis and cross-talks with myogenesis during skeletal muscle regeneration. Int J Mol Sci. 2018; 19(7) https://doi.org/10.3390/ijms19072044.

103. Gonzalez D, et al. ALS skeletal muscle shows enhanced TGF- $\beta$ signaling, fibrosis and induction of fibro/adipogenic progenitor markers. PLoS One. 2017;12(5) https://doi.org/10.1371/journal.pone.0177649. 
104. Hogarth MW, et al. Fibroadipogenic progenitors are responsible for muscle loss in limb girdle muscular dystrophy 2B. Nat Commun. 2019;10(1) https:// doi.org/10.1038/s41467-019-10438-z.

105. Lukjanenko $L$, et al. Loss of fibronectin from the aged stem cell niche affects the regenerative capacity of skeletal muscle in mice. Nat Med. 2016;22(8): 897-905 https://doi.org/10.1038/nm.4126.

106. De Micheli AJ, Spector JA, et al. A reference single-cell transcriptomic atlas of human skeletal muscle tissue reveals bifurcated muscle stem cell populations. Skelet Muscle. 2020a;10(1) https://doi.org/10.1186/s13395-02000236-3.

107. De Micheli AJ, Laurilliard EJ, et al. Single-cell analysis of the muscle stem cell hierarchy identifies heterotypic communication signals involved in skeletal muscle regeneration. Cell Rep. 2020b;30(10):3583-3595.e5 https://doi.org/1 0.1016/j.celrep.2020.02.067

108. Oprescu SN, et al. Temporal Dynamics and Heterogeneity of Cell Populations during Skeletal Muscle Regeneration. iscience. 2020;23(4) https://doi.org/10.1016/j.isci.2020.100993.

109. Rubenstein $A B$, et al. Single-cell transcriptional profiles in human skeletal muscle. Sci Rep. 2020;10(1) https://doi.org/10.1038/s41598-01957110-6.

110. Riquelme-Guzmán C, Contreras $\mathrm{O}$. Single-cell revolution unveils the mysteries of the regenerative mammalian digit tip. Dev Biol. 2020;461:107-9 https://doi.org/10.1016/j.ydbio.2020.02.002

111. Marinkovic M, et al. Fibro-adipogenic progenitors of dystrophic mice are insensitive to NOTCH regulation of adipogenesis. Life Sci Alliance. 2019;2(3) https://doi.org/10.26508/lsa.201900437.

112. Ciuffreda MC, et al. Protocols for in vitro differentiation of human mesenchymal stem cells into osteogenic, chondrogenic and adipogenic lineages. Methods Mol Biol. 2016:149-58 https://doi.org/10.1007/978-1-493 9-3584-0 8.

113. Sacchetti B, et al. No identical "mesenchymal stem cells" at different times and sites: Human committed progenitors of distinct origin and differentiation potential are incorporated as adventitial cells in microvessels. Stem Cell Rep. 2016;6(6):897-913 https://doi.org/10.1016/j. stemcr.2016.05.011.

114. Mierzejewski B, et al. Mouse CD146+ muscle interstitial progenitor cells differ from satellite cells and present myogenic potential. Stem Cell Res Ther. 2020;11(1) https://doi.org/10.1186/s13287-020-01827-z.

115. Swift J, et al. Nuclear lamin-A scales with tissue stiffness and enhances matrix-directed differentiation. Science. 2013;341(6149) https://doi.org/1 $0.1126 /$ science.1240104.

116. Lee C, et al. Rotator Cuff Fibro-Adipogenic Progenitors Demonstrate Highest Concentration, Proliferative Capacity, and Adipogenic Potential Across Muscle Groups. J Orthop Res. 2020;38(5):1113-21 https://doi.org/10.1002/ jor.24550.

117. Mázala DAG, et al. TGF- $\beta$-driven muscle degeneration and failed regeneration underlie disease onset in a DMD mouse model. JCI Insight 2020;5(6) https://doi.org/10.1172/jci.insight.135703.

118. Rodgers JT, et al. HGFA Is an Injury-Regulated Systemic Factor that Induces the Transition of Stem Cells into GAlert. Cell Rep. 2017;19(3):479-86 https:// doi.org/10.1016/j.celrep.2017.03.066.

119. Burks TN, Cohn RD. Role of TGF- $\beta$ signaling in inherited and acquired myopathies. Skelet Muscle. 2011;1(1):19 https://doi.org/10.1186/2044-504 0-1-19.

120. Lodyga $M$, Hinz B. TGF- $\beta 1$ - A truly transforming growth factor in fibrosis and immunity. Semin Cell Dev Biol. 2020:123-39 https://doi.org/10.1016/j. semcdb.2019.12.010.

121. Budi EH, Duan D, Derynck R. Transforming Growth Factor- $\beta$ Receptors and Smads: Regulatory Complexity and Functional Versatility. Trends Cell Biol. 2017:658-72 https://doi.org/10.1016/j.tcb.2017.04.005.

122. Wu MY, Hill CS. TGF- $\beta$ Superfamily Signaling in Embryonic Development and Homeostasis. Dev Cell. 2009:329-43 https://doi.org/10.1016/j.devcel.2 009.02.012.

123. David CJ, Massagué J. Contextual determinants of TGF $\beta$ action in development, immunity and cancer. Nat Rev Mol Cell Biol. 2018:419-35 https://doi.org/10.1038/s41580-018-0007-0.

124. Derynck R, Budi EH. Specificity, versatility, and control of TGF-b family signaling. Sci Signal. 2019; https://doi.org/10.1126/scisignal.aav5183.

125. Hinz B, et al. The myofibroblast: One function, multiple origins. Am J Pathol. 2007:170(6):1807-16 https://doi.org/10.2353/ajpath.2007.070112.
126. Györfi AH, Matei AE, Distler JHW. Targeting TGF- $\beta$ signaling for the treatment of fibrosis. Matrix Biol. 2018:8-27 https://doi.org/10.1016/j.ma tbio.2017.12.016

127. Hinz B. Myofibroblasts. Exp Eye Res. 2015:56-70 https://doi.org/10.1016/j. exer.2015.07.009

128. Klingberg $F$, et al. Prestress in the extracellular matrix sensitizes latent TGF$\beta 1$ for activation. J Cell Biol. 2014;207(2):283-97 https://doi.org/10.1083/jcb.2 01402006.

129. Reed $\mathrm{NI}$, et al. The av $\beta 1$ integrin plays a critical in vivo role in tissue fibrosis. Sci Transl Med. 2015;7(288) https://doi.org/10.1126/scitra nslmed.aaa5094.

130. Wang XF, et al. Expression cloning and characterization of the TGF- $\beta$ type III receptor. Cell. 1991; https://doi.org/10.1016/0092-8674(91)90074-9.

131. López-Casillas F, et al. Betaglycan can act as a dual modulator of TGF- $\beta$ access to signaling receptors: Mapping of ligand binding and GAG attachment sites. J Cell Biol. 1994; https://doi.org/10.1083/jcb.124.4.557.

132. Lewis KA, et al. Betaglycan binds inhibin and can mediate functional antagonism of activin signalling. Nature. 2000; https://doi.org/10.1038/3 5006129.

133. Wiater $E$, Vale W. Inhibin is an antagonist of bone morphogenetic protein signaling. J Biol Chem. 2003; https://doi.org/10.1074/jbc.M209710200.

134. Velasco-Loyden G, Arribas J, López-Casillas F. The Shedding of Betaglycan Is Regulated by Pervanadate and Mediated by Membrane Type Matrix Metalloprotease-1. J Biol Chem. 2004; https://doi.org/10.1074/jbc.M3064992 00 .

135. Vilchis-Landeros MM, et al. Recombinant soluble betaglycan is a potent and isoform-selective transforming growth factor- $\beta$ neutralizing agent. Biochem J. 2001; https://doi.org/10.1042/0264-6021:3550215.

136. Bilandzic $M$, et al. Betaglycan blocks metastatic behaviors in human granulosa cell tumors by suppressing NFKB-mediated induction of MMP2. Cancer Lett. 2014; https://doi.org/10.1016/j.canlet.2014.07.039.

137. Shi $Y$, Massagué J. Mechanisms of TGF- $\beta$ signaling from cell membrane to the nucleus. Cell. 2003:685-700 https://doi.org/10.1016/S0092-8674(03 )00432-X.

138. Imamura T, et al. Smad6 inhibits signalling by the TGF- $\beta$ superfamily. Nature. 1997; https://doi.org/10.1038/39355.

139. Jung SM, et al. Smad6 inhibits non-canonical TGF- $\beta 1$ signalling by recruiting the deubiquitinase A20 to TRAF6. Nat Commun. 2013; https://doi.org/10.103 8/ncomms3562

140. Nakao A, et al. Identification of Smad7, a TGFß-inducible antagonist of TGFß signalling. Nature. 1997; https://doi.org/10.1038/39369.

141. Derynck R, Zhang YE. Smad-dependent and Smad-independent pathways in TGF- $\beta$ family signalling. Nature. 2003:577-84 https://doi.org/10.1038/na ture02006.

142. Khalil H, et al. Fibroblast-specific TGF- $\beta$-Smad2/3 signaling underlies cardiac fibrosis, in. J Clin Investig. 2017:3770-83 https://doi.org/10.1172/JCl94753.

143. Kim KK, Sheppard D, Chapman HA. TGF- $\beta 1$ signaling and tissue fibrosis. Cold Spring Harb Perspect Biol. 2018;10(4) https://doi.org/10.1101/ cshperspect.a022293.

144. Juban G, et al. AMPK Activation Regulates LTBP4-Dependent TGF- $\beta 1$ Secretion by Pro-inflammatory Macrophages and Controls Fibrosis in Duchenne Muscular Dystrophy. Cell Rep. 2018;25(8):2163-2176.e6 https:// doi.org/10.1016/j.celrep.2018.10.077.

145. McLennan IS, Koishi K. Cellular localisation of transforming growth factorbeta 2 and -beta 3 (TGF- 32 , TGF- 33 ) in damaged and regenerating skeletal muscles. Dev Dyn. 1997;208(2):278-89 https://doi.org/10.1002/(sici)1097-01 77(199702)208:2<278::aid-aja14>3.0.co:2-\%23.

146. Theret, Marine, Marcela Low, Lucas Rempel, Fang Fang Li, Lin Wei Tung, Osvaldo Contreras, Chih-Kai Chang, Andrew Wu, Hesham Soliman, and Fabio M V Rossi. "In Vitro Assessment of Anti-Fibrotic Drug Activity Does Not Predict in Vivo Efficacy in Murine Models of Duchenne Muscular Dystrophy." Life Sciences 279 (2021):119482. https://doi.org/10.1016/j.lfs.2 021.119482.

147. Davies MR, et al. TGF- $\beta$ small molecule inhibitor sb431542 reduces rotator cuff muscle fibrosis and fatty infiltration by promoting fibro/ adipogenic progenitor apoptosis. PLoS One. 2016;11(5) https://doi.org/10.1371/journal. pone.0155486.

148. Saito Y, Chikenji TS, Matsumura T, Nakano M, Fujimiya M. Exercise enhances skeletal muscle regeneration by promoting senescence in fibro-adipogenic progenitors. Nat Commun. 2020;11:889 https://doi.org/10.1038/s41467-02 $0-14734-x$. 
149. Reggio A, Spada F, Rosina M, Massacci G, Zuccotti A, Fuoco C, et al. The immunosuppressant drug azathioprine restrains adipogenesis of muscle Fibro/Adipogenic Progenitors from dystrophic mice by affecting AKT signaling. Sci Rep. 2019;9 https://doi.org/10.1038/s41598-019-39538-y.

150. Dong Y, Augusto K, Silva S, Dong Y, Zhang L. Glucocorticoids increase adipocytes in muscle by affecting IL-4 regulated FAP activity. FASEB J. 2014; 28(9):4123-32 https://doi.org/10.1096/fj.14-254011.

151. Mozzetta C, et al. Fibroadipogenic progenitors mediate the ability of HDAC inhibitors to promote regeneration in dystrophic muscles of young, but not old Mdx mice. EMBO Mol Med. 2013;5(4):626-39 https://doi.org/10.1002/ emmm.201202096.

152. Liu $X$, et al. Trichostatin A regulates fibro/adipogenic progenitor adipogenesis epigenetically and reduces rotator cuff muscle fatty infiltration. J Orthop Res. 2020; https://doi.org/10.1002/jor.24865.

153. Reggio A, et al. Adipogenesis of skeletal muscle fibro/adipogenic progenitors is affected by the WNT5a/GSK3/ $\beta$-catenin axis. Cell Death Differ. 2020;27(10):2921-41 https://doi.org/10.1038/s41418-020-0551-y.

154. Cordani N, et al. Nitric oxide controls fat deposition in dystrophic skeletal muscle by regulating fibro-adipogenic precursor differentiation. Stem Cells. 2014;32(4):874-85 https://doi.org/10.1002/stem.1587.

155. leronimakis $\mathrm{N}$, et al. PDGFRa signalling promotes fibrogenic responses in collagen-producing cells in Duchenne muscular dystrophy. J Pathol. 2016; 240(4):410-24 https://doi.org/10.1002/path.4801.

156. Astudillo P. Extracellular matrix stiffness and Wnt/ $\beta$-catenin signaling in physiology and disease. Biochem Soc Trans. 2020:1187-98 https://doi.org/1 0.1042/BST20200026

157. Nusse R, Clevers H. Wnt/ $\beta$-Catenin Signaling. Dis Emerg Ther Modalities Cell. 2017:985-99 https://doi.org/10.1016/j.cell.2017.05.016.

158. Aberle $\mathrm{H}$, et al. B-Catenin Is a Target for the Ubiquitin-Proteasome Pathway. EMBO J. 1997;16(13):3797-804 https://doi.org/10.1093/emboj/16.13.3797.

159. Valenta T, Hausmann G, Basler K. The many faces and functions of $\beta$ catenin. EMBO J. 2012:2714-36 https://doi.org/10.1038/emboj.2012.150.

160. Cadigan KM, Waterman ML. TCF/LEFs and Wnt signaling in the nucleus. Cold Spring Harb Perspect Biol. 2012:4(11) https://doi.org/10.1101/ cshperspect.a007906

161. Clevers H. Wnt/ $\beta$-Catenin Signaling in Development and Disease. Cell. 2006: 469-80 https://doi.org/10.1016/j.cell.2006.10.018.

162. Trensz F, et al. A muscle resident cell population promotes fibrosis in hindlimb skeletal muscles of mdx mice through the Wnt canonical pathway. Am J Physiol Cell Physiol. 2010;299(5) https://doi.org/10.1152/a jpcell.00253.2010.

163. Biressi S, et al. A Wnt-TGF2 axis induces a fibrogenic program in muscle stem cells from dystrophic mice. Sci Transl Med. 2014;6(267) https://doi. org/10.1126/scitranslmed.3008411.

164. Xiang FL, Fang M, Yutzey KE. Loss of $\beta$-catenin in resident cardiac fibroblasts attenuates fibrosis induced by pressure overload in mice. Nat Commun. 2017:8(1):712 https://doi.org/10.1038/s41467-017-00840-w.

165. Akhmetshina, A. et al. (2012) Activation of canonical Wnt signalling is required for TGF- $\beta$-mediated fibrosis, Nature Communications, 3. doi: https://doi.org/10.1038/ncomms1734.

166. Hamburg-Shields $E$, et al. Sustained $\beta$-catenin activity in dermal fibroblasts promotes fibrosis by up-regulating expression of extracellular matrix protein-coding genes. J Pathol. 2015;235(5):686-97 https://doi.org/10.1002 path.4481.

167. Działo E, Tkacz K, Błyszczuk P. Crosstalk between the TGF- $\beta$ and WNT signalling pathways during cardiac fibrogenesis. Acta Biochim Pol. 2018; 65(3):341-9. https://doi.org/10.18388/abp.2018_2635.

168. Girardi F, Le Grand F. Wnt Signaling in Skeletal Muscle Development and Regeneration. Prog Mol Biol Transl Sci. 2018:157-79 https://doi.org/10.1016/ bs.pmbts.2017.11.026.

169. Piersma B, Bank RA, Boersema M. Signaling in fibrosis: TGF- $\beta$, WNT, and YAP/TAZ converge. Front Med. 2015; https://doi.org/10.3389/fmed.2015. 00059.

170. Lindahl $P$, et al. Pericyte loss and microaneurysm formation in PDGF-Bdeficient mice. Science. 1997;277(5323):242-5 https://doi.org/10.1126/ science. 277.5323 .242

171. Claesson-Welsh L, et al. cDNA cloning and expression of the human A-type platelet-derived growth factor (PDGF) receptor establishes structural similarity to the B-type PDGF receptor. Proc Natl Acad Sci U S A. 1989; 86(13):4917-21 https://doi.org/10.1073/pnas.86.13.4917.
172. Gronwald RGK, et al. Cloning and expression of a cDNA coding for the human platelet-derived growth factor receptor: Evidence for more than one receptor class. Proc Natl Acad Sci U S A. 1988;85(10):3435-9 https://doi. org/10.1073/pnas.85.10.3435.

173. Matsui T, et al. Isolation of a novel receptor cDNA establishes the existence of two PDGF receptor genes. Science. 1989;243(4892):800-4 https://doi. org/10.1126/science.2536956.

174. Yarden Y, et al. Structure of the receptor for platelet-derived growth factor helps define a family of closely related growth factor receptors. Nature. 1986;323(6085):226-32 https://doi.org/10.1038/323226a0.

175. Heldin C-H, Westermark B. Role of Platelet-Derived Growth Factor in Vivo. Mol Cell Biol Wound Repair. 1988:249-73 https://doi.org/10.1007/978-1-4 899-0185-9 7.

176. Kohler N, Lipton A. Platelets as a source of fibroblast growth-promoting activity. Exp Cell Res. 1974:87(2):297-301 https://doi.org/10.1016/0014-482 7(74)90484-4.

177. Hoch RV, Soriano P. Roles of PDGF in animal development. Development. 2003;130(20):4769-84 https://doi.org/10.1242/dev.00721.

178. Heldin $\mathrm{CH}$, Westermark B. Mechanism of action and in vivo role of plateletderived growth factor, physiological reviews. Am Physiol Soc. 1999;79(4): 1283-316 https://doi.org/10.1152/physrev.1999.79.4.1283.

179. Roskoski R. The role of small molecule platelet-derived growth factor receptor (PDGFR) inhibitors in the treatment of neoplastic disorders. Pharmacol Res. 2018:65-83 https://doi.org/10.1016/j.phrs.2018.01.021.

180. Kazlauskas A. PDGFs and their receptors. Gene. 2017:1-7 https://doi.org/10.1 016/j.gene.2017.03.003

181. Kanakaraj $P$, et al. Ligand-Induced Interaction between $a$ - and $\beta$-Type Platelet-Derived Growth Factor (PDGF) Receptors: Role of Receptor Heterodimers in Kinase Activation. Biochemistry. 1991;30(7):1761-7 https:// doi.org/10.1021/bi00221a005.

182. Kelly JD, et al. Platelet-derived growth factor (PDGF) stimulates PDGF receptor subunit dimerization and intersubunit trans-phosphorylation. J Biol Chem. 1991;266(14):8987-92 https://doi.org/10.1016/s0021-9258(1 8)31541-2.

183. Wang $Y$, et al. Platelet-derived Growth Factor Receptor-mediated Signal Transduction from Endosomes. J Biol Chem. 2004;279(9):8038-46 https://doi. org/10.1074/jbc.M311494200

184. Mueller AA, et al. Intronic polyadenylation of PDGFRa in resident stem cells attenuates muscle fibrosis. Nature England. 2016;540(7632):276-9 https://doi. org/10.1038/nature20160.

185. Sugg KB, et al. Inhibition of platelet-derived growth factor signaling prevents muscle fiber growth during skeletal muscle hypertrophy. FEBS Letters. 2017;591(5):801-9 https://doi.org/10.1002/1873-3468.12571. John Wiley \& Sons, Ltd

186. Asli NS, et al. PDGFRa signaling in cardiac fibroblasts modulates quiescence, metabolism and self-renewal, and promotes anatomical and functional repair. bioRxiv. 2019a:225979 https://doi.org/10.1101/225979.

187. Ivey MJ, et al. Platelet-derived growth factor receptor-a is essential for cardiac fibroblast survival. Am J Physiol Heart Circ Physiol. 2019:317(2):H33044 https://doi.org/10.1152/ajpheart.00054.2019.

188. Harvey T, Flamenco S, Fan CM. A Tppp3 + Pdgfra + tendon stem cell population contributes to regeneration and reveals a shared role for PDGF signalling in regeneration and fibrosis. Nat Cell Biol. 2019;21(12):1490-503 https://doi.org/10.1038/s41556-019-0417-z

189. Liu W, et al. Intramuscular adipose is derived from a non-Pax3 lineage and required for efficient regeneration of skeletal muscles. Dev Biol. 2012;361(1): 27-38 https://doi.org/10.1016/j.ydbio.2011.10.011.

190. Tchoukalova YD, Sarr MG, Jensen MD. Measuring committed preadipocytes in human adipose tissue from severely obese patients by using adipocyte fatty acid binding protein. Am J Physiol Regul Integr Comp Physiol. 2004; 287(5 56-5) https://doi.org/10.1152/ajpregu.00337.2004.

191. Biltz NK, Meyer GA. A novel method for the quantification of fatty infiltration in skeletal muscle. Skelet Muscle. 2017:7(1) https://doi.org/10.11 86/s13395-016-0118-2.

192. Pisani DF, et al. Mouse model of skeletal muscle adiposity: A glycerol treatment approach. Biochem Biophys Res Commun. 2010;396(3):767-73 https://doi.org/10.1016/j.bbrc.2010.05.021

193. Shabalina IG, et al. UCP1 in Brite/Beige adipose tissue mitochondria is functionally thermogenic. Cell Rep. 2013;5(5):1196-203 https://doi.org/10.1 016/j.celrep.2013.10.044. 
194. Gorski T, Mathes S, Krützfeldt J. Uncoupling protein 1 expression in adipocytes derived from skeletal muscle fibro/adipogenic progenitors is under genetic and hormonal control. J Cachexia Sarcopenia Muscle. 2018; 9(2):384-99 https://doi.org/10.1002/jcsm.12277.

195. Saely CH, Geiger K, Drexel H. Brown versus white adipose tissue: A minireview. Gerontology. 2011:15-23 https://doi.org/10.1159/000321319.

196. Vishvanath L, Gupta RK. Contribution of adipogenesis to healthy adipose tissue expansion in obesity. J Clin Invest. 2019:4022-31 https://doi.org/10.11 72/JCl129191.

197. Schulz TJ, Tseng YH. Brown adipose tissue: Development, metabolism and beyond. Biochem J. 2013:167-78 https://doi.org/10.1042/BJ20130457.

198. Bettica $P$, et al. Histological effects of givinostat in boys with Duchenne muscular dystrophy. Neuromuscul Disord. 2016;26(10):643-9 https://doi. org/10.1016/j.nmd.2016.07.002.

199. Minetti GC, et al. Functional and morphological recovery of dystrophic muscles in mice treated with deacetylase inhibitors. Nat Med. 2006;12(10): 1147-50 https://doi.org/10.1038/nm1479.

200. Sandonà $M$, et al. HDAC inhibitors tune miRNAs in extracellular vesicles of dystrophic muscle-resident mesenchymal cells. EMBO Rep. 2020a;21(9) https://doi.org/10.15252/embr.202050863.

201. Saccone $V$, et al. HDAC-regulated myomiRs control BAF60 variant exchange and direct the functional phenotype of fibro-adipogenic progenitors in dystrophic muscles. Genes Dev. 2014;28(8):841-57 https://doi.org/10.1101/ gad.234468.113.

202. Hu F, et al. CCN1 induces adipogenic differentiation of fibro/adipogenic progenitors in a chronic kidney disease model. Biochem Biophys Res Commun. 2019;520(2):385-91 https://doi.org/10.1016/j.bbrc.2019.10.047.

203. Cerquone Perpetuini $A$, et al. Janus effect of glucocorticoids on differentiation of muscle fibro/adipogenic progenitors. Sci Rep. 2020;10(1) https://doi.org/10.1038/s41598-020-62194-6.

204. Fardet L, Petersen I, Nazareth I. Prevalence of long-term oral glucocorticoid prescriptions in the UK over the past 20 years. Rheumatology (Oxford, England). 2011:50(11):1982-90 https://doi.org/10.1093/rheumatology/ker017.

205. McDonald CM, et al. Long-term effects of glucocorticoids on function, quality of life, and survival in patients with Duchenne muscular dystrophy: a prospective cohort study. Lancet. 2018;391(10119):451-61 https://doi.org/1 0.1016/S0140-6736(17)32160-8.

206. Ricotti $\vee$, et al. Long-term benefits and adverse effects of intermittent versus daily glucocorticoids in boys with Duchenne muscular dystrophy. J Neurol Neurosurg Psychiatry. 2013;84(6):698-705 https://doi.org/10.1136/jnnp-2 012-303902

207. Palma, A. et al. (2019) Myo-REG: A portal for signaling interactions in muscle regeneration, Frontiers in Physiology, 10(SEP). doi: https://doi.org/10.3389/ fphys.2019.01216.

208. Oishi T, et al. Osteogenic Differentiation Capacity of Human Skeletal MuscleDerived Progenitor Cells. PLoS One. 2013;8(2) https://doi.org/10.1371/journa I.pone.0056641.

209. Meyers C, et al. Heterotopic Ossification: A Comprehensive Review. JBMR Plus. 2019;3(4):e10172 https://doi.org/10.1002/jbm4.10172

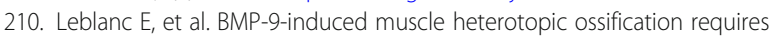
changes to the skeletal muscle microenvironment. J Bone Miner Res. 2011; 26(6):1166-77 https://doi.org/10.1002/jbmr.311.

211. Wosczyna MN, et al. Multipotent progenitors resident in the skeletal muscle interstitium exhibit robust BMP-dependent osteogenic activity and mediate heterotopic ossification. J Bone Miner Res. 2012;27(5):1004-17 https://doi. org/10.1002/jbmr.1562.

212. Glass GE, et al. TNF-a promotes fracture repair by augmenting the recruitment and differentiation of muscle-derived stromal cells. Proc Natl Acad Sci U S A. 2011;108(4):1585-90 https://doi.org/10.1073/pnas.10185011 08.

213. Abou-Khalil R, et al. Autocrine and Paracrine Angiopoietin 1/Tie-2 Signaling Promotes Muscle Satellite Cell Self-Renewal. Cell Stem Cell. 2009;5(3):298309 https://doi.org/10.1016/j.stem.2009.06.001.

214. De Palma M, et al. Tie2 identifies a hematopoietic lineage of proangiogenic monocytes required for tumor vessel formation and a mesenchymal population of pericyte progenitors. Cancer Cell. 2005;8(3):211-26 https://doi. org/10.1016/j.ccr.2005.08.002.

215. Bozycki L, et al. Whole-body clearing, staining and screening of calcium deposits in the mdx mouse model of Duchenne muscular dystrophy. Skelet Muscle. 2018;8(1) https://doi.org/10.1186/s13395-018-0168-8.
216. Pawlikowski, B. et al. (2019) A cellular atlas of skeletal muscle regeneration and aging, bioRxiv, p. 635805. doi: https://doi.org/10.1101/635805.

217. Bentzinger CF, et al. Cellular dynamics in the muscle satellite cell niche. EMBO Rep. 2013:1062-72 https://doi.org/10.1038/embor.2013.182.

218. Chiristov C, Chrétien F, Abou-Khalil R, Bassez G, Vallet G, Authier FJ, et al. Muscle satellite cells and endothelial cells: Close neighbors and privileged partners. Mol Biol Cell. 2007;18:1397-409 https://doi.org/10.1091/mbc.E0608-0693.

219. Latroche $C$, et al. Skeletal muscle microvasculature: A highly dynamic lifeline. Physiology. 2015:417-27 https://doi.org/10.1152/physiol.00026.2015.

220. Bonfanti C, et al. PW1/Peg3 expression regulates key properties that determine mesoangioblast stem cell competence. Nat Commun. 2015;6 https://doi.org/10.1038/ncomms7364.

221. Tedesco FS, Moyle LA, Perdiguero E. Muscle interstitial cells: A brief field guide to non-satellite cell populations in skeletal muscle. Methods Mol Biol. 2017:129-47 https://doi.org/10.1007/978-1-4939-6771-1_7.

222. Chazaud B. Inflammation and Skeletal Muscle Regeneration: Leave It to the Macrophages! Trends Immunol. 2020:481-92 https://doi.org/10.1016/j.it.202 0.04.006.

223. Juban G, Chazaud B. Metabolic regulation of macrophages during tissue repair: insights from skeletal muscle regeneration. FEBS Letter. 2017:3007-21 https://doi.org/10.1002/1873-3468.12703.

224. Theret M, Mounier R, Rossi F. The origins and non-canonical functions of macrophages in development and regeneration. Development (Cambridge). 2019;146(9) https://doi.org/10.1242/dev.156000.

\section{Publisher's Note}

Springer Nature remains neutral with regard to jurisdictional claims in published maps and institutional affiliations.
Ready to submit your research? Choose BMC and benefit from:

- fast, convenient online submission

- thorough peer review by experienced researchers in your field

- rapid publication on acceptance

- support for research data, including large and complex data types

- gold Open Access which fosters wider collaboration and increased citations

- maximum visibility for your research: over $100 \mathrm{M}$ website views per year

At $\mathrm{BMC}$, research is always in progress.

Learn more biomedcentral.com/submissions 